\title{
Genome-Wide Transcriptional Response of Saccharomyces cerevisiae to Stress-Induced Perturbations
}

\author{
Hilal Taymaz-Nikerel, Ayca Cankorur-Cetinkaya and Betul Kirdar* \\ Department of Chemical Engineering, Bogazici University, Istanbul, Turkey
}

Cells respond to environmental and/or genetic perturbations in order to survive and proliferate. Characterization of the changes after various stimuli at different -omics levels is crucial to comprehend the adaptation of cells to the changing conditions. Genomewide quantification and analysis of transcript levels, the genes affected by perturbations, extends our understanding of cellular metabolism by pointing out the mechanisms that

OPEN ACCESS

Edited by:

Josselin Noirel,

Conservatoire National des Arts et Métiers, France

Reviewed by: Trong K. Pham, University of Sheffield, UK

Nuno Pereira Mira,

Instituto Superior Técnico; Institute

for Biotechnology and

Bioengineering, Portugal

*Correspondence:

Betul Kirdar

kirdar@boun.edu.tr

Specialty section:

This article was submitted to

Systems Biology,

a section of the journal

Frontiers in Bioengineering and

Biotechnology

Received: 02 September 2015 Accepted: 04 February 2016

Published: 18 February 2016

Citation:

Taymaz-Nikerel H, CankorurCetinkaya A and Kirdar B (2016) Genome-Wide Transcriptional Response of Saccharomyces cerevisiae to Stress-Induced

Perturbations.

Front. Bioeng. Biotechnol. 4:17. doi: 10.3389/fbioe.2016.00017 play role in sensing the stress caused by those perturbations and related signaling pathways, and in this way guides us to achieve endeavors, such as rational engineering of cells or interpretation of disease mechanisms. Saccharomyces cerevisiae as a model system has been studied in response to different perturbations and corresponding transcriptional profiles were followed either statically or/and dynamically, short and long term. This review focuses on response of yeast cells to diverse stress inducing perturbations, including nutritional changes, ionic stress, salt stress, oxidative stress, osmotic shock, and to genetic interventions such as deletion and overexpression of genes. It is aimed to conclude on common regulatory phenomena that allow yeast to organize its transcriptomic response after any perturbation under different external conditions.

Keywords: yeast, transcriptome, perturbation, regulation, stress

\section{INTRODUCTION}

The central challenge in systems biology is to construct the whole life model for the prediction of cellular response to the changing environments. Therefore, the genome-level understanding of the cellular response to both genetic and environmental perturbations is extremely important in modeling. Consequently, systematic perturbation experiments were conducted to reach this goal. Saccharomyces cerevisiae has been investigated in biochemical and genetics laboratories for many decades, since it is considered to be a good model organism. Cellular response of this organism at different -omics levels to different perturbations has also been extensively studied by systematically introducing environmental changes. The availability of a deletion collection made it also an attractive organism to screen the cellular response to deletions of specific genes. The systems biology-based studies resulted in the understanding of several pathways and the cellular behavior of the yeast cells to different perturbations. Although it is probably the best-understood organism, we are still far away from modeling the response of this organism to perturbations (Boone, 2014).

Eukaryotic cells reprogram the expression of those genes that are essential for adapting to the changing conditions as a response to perturbation. Microarray technology allowed investigation 
of expression profiles of thousands (whole-genome arrays) or hundreds (low-density arrays) of genes simultaneously. ArrayExpress at the European Bioinformatics Institute (EBI) and the Gene Expression Omnibus (GEO) database at the National Center for Biotechnology Information (NCBI) are the two major public databases of microarray data (Barrett et al., 2013; Kolesnikov et al., 2015). Although they have different designs, both databases support the minimum information about a microarray experiment (MIAME), a standard guideline for describing a microarray experiment (Brazma et al., 2001). The establishment of RNA-seq, providing detailed measurement, and lower technical discrepancy, became another attractive analytical tool in transcriptomics (Nagalakshmi et al., 2008; van Dijk et al., 2011; Nookaew et al., 2012). Most of the high-throughput data have been generated by sampling the experimental system at singletime point. Generation of the time-series gene expression data is considered to be very important to understand the dynamic nature of biological systems. The efforts to study and model such dynamic data were reviewed in detail by Bar-Joseph et al. (2012), Yosef and Regev (2011), and Secrier and Schneider (2014).

The programing of gene expression in cells occurs on a broad range of time-scales from rapid responses (minutes to hours of response to environmental stresses) to slower (hours to days during development) processes (Yosef and Regev, 2011). An early analysis of the transcriptomic response of yeast cells to diverse environmental changes indicated that a large set of genes ( 900) showed a comparable and severe response to different perturbations sensing them as an environmental stress [environmental stress response (ESR)]. The upregulated genes were related to stress defense regulated by Msn2p and Msn4p and downregulated genes were associated with ribosome biogenesis and protein synthesis. An important observation to be noted was the involvement and the regulation of different isoenzymes in response to several perturbations (Gasch et al., 2000; Causton et al., 2001; Gasch, 2003). Positive and negative regulators of protein kinase A (PKA) pathway were also reported to be induced within the ESR genes (Gasch et al., 2000). This common response to perturbations was reported to be important for preparing cells in response to further possible changes in the environment (Berry and Gasch, 2008; Mitchell et al., 2009) leading to stress (cross-) tolerance. However, it should be noted that the correlation between upregulation of gene expression and its requirement for fitness was not always significant (Giaever et al., 2002; Giaever and Nislow, 2014).

Zakrzewska et al. (2011) used yeast haploid deletion collection to find the genes and their related functions involved in the stress survival and in the gain of stress tolerance. Survival analysis of the yeast cells revealed that a general stress response (GSR) increases survival after a period of mild stress pretreatment, and this survival of stress was negatively correlated with mutant growth rate. Resistance to stress and corresponding tolerance gained, induced by severe perturbations in S. cerevisiae, are directed by specific processes for each stress and at the same time by general processes for all stresses. Growth rate was acknowledged for being responsible for tolerating stress and growth rate reduction was found to be responsible for gaining tolerance to stress. Transcriptomic analysis in response to several perturbations in chemostats at different growth rates indicated that there was a notable correlation between the growth rate-dependent genes and ESR genes (Gasch et al., 2000; Regenberg et al., 2006; Castrillo et al., 2007; Brauer et al., 2008; Fazio et al., 2008). It has been proposed that most of the alterations in the expression of ESR genes are associated with the lowered growth rate as a result of a change in the environment. Msn2p and Msn4p are found to be important in the organization of transcriptome, but not in the observed changes, in the phenotype due to changes in the growth rate (Zakrzewska et al., 2011). Components of stress-specific signaling pathways and effectors of these pathways intervening functional adaptation in response to changes in environmental conditions have been identified (Chasman et al., 2014). An extensive review of signaling pathways that control proliferation versus stress defense in yeast and mammalian cells was recently provided (Ho and Gasch, 2015).

Transcriptomic data obtained from perturbation experiments are an extremely important step in the construction of large scale, system-based models that can be used to predict the cellular response to perturbations. The integration of this data with other -omics, pathway information, computational, and statistical tools, is crucial to improve the accuracy in the prediction capabilities of the models. However, it is important to note that these experiments should be carefully designed and interpreted according to the needs of the investigators. In the present review, systematically introduced perturbations to monitor the wholegenome level transcriptomic response of $S$. cerevisiae cells to these perturbations will be summarized. Most commonly studied stress-causing perturbations, such as the changes in the types and quantities of available nutrients, oxidative reagents, temperature, osmolarity, and the metal ions, were selected to review. Moreover, these perturbations are closely related to the optimization of industrial applications and to human diseases. Although we review each perturbation in a different section, it is not always possible to analyze only one stress factor alone. For example, during fermentation, $S$. cerevisiae wine strains undergo considerable stress due to the high concentrations of sugars, producing high osmotic pressure, followed by ethanol accumulation, addition to nitrogen limitation, low $\mathrm{pH}$, and the presence of $\mathrm{SO}_{2}$, all imposing pressure on the cells (Treu et al., 2014).

\section{TRANSCRIPTOMIC RESPONSE TO NUTRITIONAL CHANGES}

The ability of living organisms to acclimate to alterations in their nutritional environment is necessary for their survival, and they have developed mechanisms to cope with the new conditions quickly and effectively. Yeast cells sense the nutrients in the environment via a group of major nutrient-signaling pathways, which coordinate general responses, such as cellular proliferation and stress resistance. Systematic perturbation experiments were performed to understand the underlying molecular mechanisms responsible for this adaptation process to the changes in the environment. The response and tolerance to nutrient-relevant stresses have been largely reviewed by Teixeira et al. (2011) and Conrad et al. (2014). Our focus here will be to review the selected studies on the transcriptomic response of $S$. cerevisiae to nutrient limitations and to transient changes in the nutrient environment 
as well as on the studies aiming to elucidate the nutrient-signaling pathways.

\section{Response to Nutrient Limitations}

Nutrient limitation has drawn the attention of researchers, because microorganisms encounter nutrient limitation in their natural environments and during industrial processes. The first genomewide transcriptome analysis in S. cerevisiae by DeRisi et al. (1997) investigated the response of yeast cells at transcriptomic level during the diauxic shift using microarrays. This pioneering work indicated that the passage from a glucose rich medium to a glucose-depleted medium involves the integration of a number of major signaling and regulatory pathways. These environmental perturbation experiments revealed that glucose depletion leads to the induction of cytochrome $c$-related genes and the genes involved in the TCA/glyoxylate cycle and carbohydrate storage and to the repression of those involved in protein synthesis, including ribosomal proteins, tRNA synthetases, and translation, elongation, and initiation factors. They further investigated the genome-wide transcriptional response to the deletion of TUP1, general transcription repressor, and to the overexpression of YAP1, transcription activator, to understand the contribution of those individual regulatory proteins to the reprograming of transcriptional response to glucose. These genetic perturbation experiments revealed the group of genes, expression of which was altered by the deletion of these transcription factors (DeRisi et al., 1997). These results demonstrated for the first time that microarray technology is a useful tool for the genome-wide exploration of expression patterns of genes upon environmental and genetic perturbations. Transcriptional alterations resulting from deletion or overexpression of regulatory molecules identified by this approach were used to dissect and characterize regulatory pathways and networks.

Gasch et al. (2000) examined the temporal transcriptomic changes in yeast cells in batch cultures exposed to amino acid starvation or to nitrogen depletion for a period of $6 \mathrm{~h}$ and reported the alteration in the expression levels of ESR genes under both conditions. The genes involved in carbohydrate metabolism, detoxification of reactive oxygen species (ROS), cellular redox reactions, cell wall modification, protein folding and degradation, DNA damage repair, fatty acid metabolism, metabolite transport, vacuolar and mitochondrial functions, autophagy, and intracellular signaling were found to be induced and the genes related to growth-related processes and ribosome biogenesis were reported to be repressed. Furthermore, the transcriptomic analysis of the strains carrying deletion of Msn2p, Msn4p, and both of these factors revealed that the majority of ESR genes were under the control of Msn2p and Msn4p. Starvation-specific response of yeast cells was reported to be related to switch from active growth to a growth-arrested state.

The observation of the effect of changing growth rates on the transcriptomic response to changes in the nutrient environment resulted in a shift of mode of fermentations from batch to chemostat with a constant growth rate. Boer et al. (2003) carried out the analysis of the transcriptome of S. cerevisiae cells under carbon-, nitrogen-, phosphorus-, or sulfur-limitation, at a dilution rate of $0.1 \mathrm{~h}^{-1}$. This study revealed the significant alterations in the expression levels of $31 \%$ of genes between at least two growth conditions. The genes involved in the uptake and phosphorylation of glucose, uptake and metabolism of fatty acids and storage carbohydrates, glyoxylate cycle, and gluconeogenesis, uptake and utilization of alternative carbon sources were upregulated under carbon limitation in addition to the induction of the few genes involved in the protection against oxidative stress. The expression levels of the genes involved in the transport such as low or moderate affinity hexose transporters, the genes involved in the glucose repression, cell proliferation, and differentiation were downregulated under glucose limitation when compared with three other conditions. Under nitrogen limitation, the genes involved in the metabolism of nitrogen-containing compound were observed to be upregulated, and the promoter analysis of coregulated genes revealed that Gln3p, Gat1p, Dal80p, and Gzf3p have important roles in the regulation of genes under nitrogen catabolite repression. Under phosphate limitation, the genes implicated in the uptake and metabolism of inositol phosphate, in the phosphate metabolism, and in the process of phosphorylation of metabolites were found to be induced. From promoter analysis, Pho4p was predicted to be the regulator of these events. Under sulfur limitation, the upregulation of the genes associated with the uptake of sulfate and sulfur-containing molecules and with the sulfur assimilation process was observed. Promoter analysis predicted that the transcription factors including Chf1p-Met4p-Met28p complex, Met31p, and Met32p are involved in the regulation of these genes. The genes involved in the glycogen metabolism, in the export of sulfite and in copper transportation were found to be repressed under phosphate limitation, and the majority of these downregulated genes were predicted to be dependent on Msn2p and Msn4p. It has been suggested that the cellular metabolism reorganized to encounter the needs for nutrient-limited growth of the yeast cells (Boer et al., 2003). Wu et al. (2004) have also examined the genome-wide transcriptome of yeast under five (glucose, ethanol, ammonium, phosphate, and sulfate) different nutrient-limited conditions at a dilution rate of $0.1 \mathrm{~h}^{-1}$. The genes affected under each condition were identified with the comparison to its corresponding steady state. This study revealed that the genes involved in the TCA cycle, oxidative phosphorylation, and the genes encoding high-affinity glucose transporters were upregulated under glucose-limited condition. The genes involved in glyoxylate cycles, gluconeogenesis, and nitrogen catabolite repression were upregulated under ethanol-limited conditions even in the presence of sufficient levels of nitrogen in the medium. An interesting result from this study was the observation of the activation of iron-associated genes, including FTH1, FET3, FRE3, FIT2, and FIT3, by glycolysis. The variances between these two investigations may stem from the differences in the strain background, in the experimental conditions, and in the analysis of data.

The relationship between growth rate and response to nutrient limitations draws the attention of many researchers (Castrillo et al., 2007; Boer et al., 2008, 2010; Brauer et al., 2008; Slavov and Botstein, 2011, 2013). Castrillo et al. (2007) have investigated the effect of the growth rate on the transcriptional, metabolic, and proteomic responses to nutritional changes in yeast with a special emphasis on TOR pathway. The experiments were carried out at 
growth rates of $0.07,0.1$, and $0.2 \mathrm{~h}^{-1}$ under four different nutrient limitations (glucose, ammonium, phosphate, and sulfate) in chemostats. Data analysis was performed by comparing the nutrient limited with nutrient sufficient condition in each case. This study revealed a common response to increase the growth rates in yeast at all omics levels under all nutrient limiting conditions. The genes upregulated with the increasing growth rate and independent of the nutritional limitation were found to be involved in the processes related to translation initiation, ribosome biogenesis, protein biosynthesis, RNA metabolism, nucleic acid metabolism, nucleus import/export, and proteasome function. The downregulated genes were implicated in biological processes related to the response to external stimulus, cell transduction, autophagy, homeostasis, response to stress, and vesicle recycling within Golgi. It has been suggested that these groups of genes might be involved in maximizing the efficient use of cellular resources in each limiting condition at each different growth rate. Furthermore, it has been demonstrated in this study that most of the genes regulated with growth rates are also targets of the TOR signaling pathway. The models to explain the regulation of metabolic fluxes of carbon/nitrogen, sulfur/folate, and leucine biosynthesis at the protein level were constructed through the integration of quantitative proteomic and metabolomic data.

Brauer et al. (2008) also studied the relationship between the growth rate, entry into cell cycle, glucose metabolism, and the transcriptomic response to different nutritional limitations (i.e., glucose, ammonium, sulfate, phosphate, uracil, or leucine) in 36 steady-state conditions. The transcript levels of $\sim 27 \%$ of all yeast genes were found to be either positively or negatively correlated with growth rate, independent of any nutrient limitation, and provided further support for the results published by Castrillo et al. (2007). The genes involved in ribosomal functions and stress response were found to be positively correlated with growth rate, whereas the genes involved in peroxisomal functions were identified to be negatively correlated with growth rate. The relationship between growth rate and cell-cycle population in G0/G1 phase was also linear independent of limiting nutrient. They have also constructed a linear model, based on the gene expression values, to predict relative "instantaneous growth rate" in both batch and continuous cultures. The observation of the complete consumption of glucose and failure in arresting in cell cycle, when the growth of the auxotrophic strains is limited by the auxotrophic requirements, led researchers to investigate this phenomenon further.

Analysis of the transcriptomic response of auxotropic yeast cells grown in chemostat cultures limited only with their respective auxotrophic requirements, at different growth rates, indicated a decoupling of growth rate response (GRR) from nutrient signaling, and the magnitude of the response was found to be less than that recorded in prototrophs. It has been suggested that growth rate signal is important in the regulation of fermentation/ respiration, the GRR, and the cell division cycle (Brauer et al., 2008; Slavov and Botstein, 2013).

\section{Response to Transient Nutrient Changes}

The reorganization of the transcriptomic and/or metabolomic response to transient changes in the nutrient environment was investigated by the impulse-like addition of the limited nutrient into yeast cells grown in chemostats under a specific nutrient limitation. The dynamic adaptation to the changing concentration of the nutrient was followed in time-course experiments after the perturbation of the steady state by the addition of the limited nutrient.

Kresnowati et al. (2006) studied transcriptional and metabolic response of yeast cells within the initial $5 \mathrm{~min}$ of the perturbation when aerobic, tightly controlled glucose-limited chemostat cultures were subject to a glucose pulse, and a new insight could be provided for the temporal organizations of metabolic and transcriptional events. This study provided the first example of the integration of transcriptome with metabolic changes during the initial response (minutes) to a well-defined perturbation of S. cerevisiae cells. They have shown that although metabolic and transcriptomic data are well correlated, the changes in metabolite concentrations were observed in seconds, and the changes in the transcriptomic response were detected later. Cells have responded to this increasing glucose level at transcriptional and metabolic level in order to adapt to the change from respiratory to respirofermentative metabolism and to growth acceleration. The same group has also studied the long-term response of yeast cells to a glucose pulse and depletion of oxygen by investigating the dynamic adaptation of $S$. cerevisiae grown in aerobic, glucose-limited chemostat cultures to an anaerobic pulse of glucose for a longer period of time $(5,10,30,60$, and $120 \mathrm{~min})$. The fact that onethird of the genes were significantly and differentially expressed indicated an important reprograming and strong response of the cells after the pulse. Most of these genes were found to be related to growth and carbon catabolite repression. The expression levels of several genes, including the genes encoding ribosomal biogenesis and ribosomal proteins, were changed in opposite direction 30 min after the pulse (van den Brink et al., 2008).

Bradley et al. (2009) have also shown the coordinated changes between the transcriptome and metabolome by analyzing the dynamic transcriptomic and metabolomic response of yeast cells grown on filters to glucose and ammonium starvation and developed an integrative approach based on Bayesian framework to predict metabolite-transcript correlations.

Dikicioglu et al. $(2011,2012)$ investigated the transcriptional response in the short (seconds) and long term (hours), by introducing a glucose pulse to a glucose-limited culture and an ammonium pulse to an ammonium-limited culture of yeast cells. The integration of the transcriptomic data from these perturbation experiments with two different network-based approaches presented further information about the time-based regulation of transcriptional reorganization of yeast cells under these conditions. Integration of this transient transcriptome data with the corresponding metabolome data combined with metabolic pathway information revealed the whole-genome level long-term reorganization of the yeast cells. The changes in the transcriptome and metabolome from an initial limited state, followed by a sudden pulse and then by returning to the limited state were identified for the first time in this study. The transient organization of the de novo biosynthetic pathways and salvage pathways under these conditions was reported through integration of transcriptome and metabolome. 


\section{Nutrient Signaling}

The sensing and signaling networks that direct the transcriptional and metabolic reorganization in response to the changing nutritional conditions were subject to several studies and reviewed largely by Zaman et al. (2008). In order to understand the regulation of transcriptional response of yeast cells to glucose, the transcriptomic data of the selected yeast strains that carry conditional alleles in response to glucose perturbation were analyzed. The integration of genetic knowledge with microarray analysis revealed the presence of five interlocking pathways in glucose signaling. PKA and PKB (Sch9p) were found to be the main regulators, whereas $\mathrm{Snf} 1$ and Rgt pathways have restricted roles in the regulation of the transcriptomic response to glucose. A schematic model illustrating the glucose signaling network was constructed. The perception of the environmental nutrients by the cell was reported to be the main determinant of growth rate-dependent organization of transcriptomic response (Zaman et al., 2009).

Livas et al. (2011) investigated the genome-wide transcriptional response of wild-type yeast cells and two suppressor strains lacking PKA activity when grown on ethanol and exposed to glucose for $30 \mathrm{~min}$. This study revealed the set of genes, which are induced or repressed by glucose either dependent or independent of PKA activity. Induction of the genes involved in glucose metabolism and repression of the genes involved in the utilization of alternative carbon sources were found to be exclusively controlled by other pathways and independent of PKA. The genes involved in amino acid synthesis were found to be regulated by PKA, and the response to glucose is transient. The genes regulated by redundant PKA-dependent and PKA-independent signaling pathways included the genes encoding glucose transporters, ribosomal proteins, and the genes involved in the utilization of nonfermentable carbon sources. A fourth group of genes was found to be regulated by the cooperative signaling pathways, including PKA. This study provided additional support that PKA signaling is an important player in the reorganization of the transcriptomic response of $S$. cerevisiae to glucose.

Hughes Hallett et al. (2014) examined the TOR kinase complex I (TORC1) pathway, which has a key role in the regulation of cell growth, by investigating the changes in the yeast transcriptome in response to various perturbations, including glucose starvation and nitrogen starvation for $20 \mathrm{~min}$. Under glucose starvation, PPA2 branch of TORC1 pathway has a low level activity, whereas Sch9 branch was completely switched off. The transcriptomic analysis of SNF1 deleted strains indicated that cAMP activated kinase (Snf1p) represses TORC1-Sch9 signaling but hyper-inactivates TOR-PPA2 signaling indicating that Snf1p regulates the TORC1 pathway. However, the presence of additional factors remains to be elucidated. Under nitrogen starvation, TORC1-Sch9 signaling was found to be inactive, whereas TORC1-PPA2 signaling has a high activity. The analysis of the corresponding deletion strains showed that the regulators of the TORC1, Gtr1p/Gtr2p, Npr2p/ Npr3p, and Rholp have important roles in nitrogen or amino acid starvation.

In a recent study, Oliveira et al. (2015) investigated the dynamic regulation of nitrogen metabolism by TORC1 pathway in yeast cells by analyzing transcriptome, proteome, and metabolome data. Codesigning of a perturbation matrix to follow the changes at different omics levels and the use of probabilistic model-based analysis that incorporates the prior knowledge resulted in the identification of putative targets and inputs of TORC1 including a novel putative glutamine signal.

In order to understand the pleiotropic role of the PAS kinase Rim15p in the integration of nutrient-signaling networks, such as TOR, PKA, and the Pho80-Pho85 kinase pathways, the transcriptomic responses of prototrophic RIM15 deletion mutant and a congenic RIM15 reference strain of $S$. cerevisiae were comparatively analyzed. Cells were grown under severe calorie restriction in anaerobic retentostat cultures near nongrowing conditions. This study revealed the important function of Rim15p in cell-cycle arrest and in the integration of nutrient sensing and signaling pathways under nutrient-depleted conditions (Bisschops et al., 2014).

The details of all these nutritional perturbation experiments in S. cerevisiae cells are summarized in Table 1. Many aspects of the response to limitation of C-, N-, S-, and P-sources could be revealed, and the details of the growth-regulated response could be elucidated as well as a wealth of information about transcriptional reorganization in response to the changing nutritional environment that was provided by the above mentioned studies. It is important to keep in mind that the information coming from different studies is far away from being integrated into a model due to the differences in the strain background or in the experimental design. Moreover, the use of different algorithms to analyze and interpret the data provokes an additional difficulty in the comparison or integration of these findings. The challenge continues to identify the nutrition signaling pathways by specifically designed experiments on the basis of these observations. It is important to design an experimental platform to analyze and integrate the response to nutritional changes at different omics levels from wild-type as well as from specifically selected strains, based on the previous knowledge.

\section{TRANSCRIPTOMIC RESPONSE TO OXIDATIVE PERTURBATIONS}

Exposure to oxidative agents causes the production of ROS, which are known to cause severe cellular damage and be involved in cellular processes, such as aging and apoptosis, as well as in the molecular pathogenesis of several severe disorders. The detailed information on cellular antioxidant systems, which protect yeast cells against ROS accumulation, can be found in the reviews (Farrugia and Balzan, 2012; Morano et al., 2012). Oxidative agents used to investigate oxidative stress response (OSR) are hydrogen peroxide, lipid hyperoxides, organic hydroperoxides, such as cumene hydroperoxide (CHP), linoleic acid hydroperoxide, superoxide anion, and heavy metals, such as $\mathrm{Fe}^{2+}$ and $\mathrm{Cd}$. A systematic analysis of yeast deletion mutants revealed that the genes involved in the OSR, induced by different agents, consists of a set of genes known as "core genes," which are observed under a wide variety of oxidative stress condition and another group of genes known as the "oxidant specific" genes (Thorpe et al., 2004). Several perturbation studies were carried out to investigate the dynamic transcriptomic response of yeast cells to oxidative stress 
TABLE 1 | Nutritional perturbation experiments in S. cerevisiae cultures.

\begin{tabular}{|c|c|c|c|c|}
\hline Perturbation & Experiment type & Exposure (sampling) time & $\begin{array}{l}\text { Measurement } \\
\text { technique }\end{array}$ & Reference \\
\hline \multicolumn{5}{|l|}{ Nutrient limitations } \\
\hline $\begin{array}{l}\text { From glucose rich to glucose-depleted medium (Diauxic } \\
\text { shift) }\end{array}$ & NA & From 9 to $21 \mathrm{~h}$ & cDNA microarrays & $\begin{array}{l}\text { DeRisi et al. } \\
(1997)\end{array}$ \\
\hline From glucose grown to amino acid starvation & Shake flasks & $\begin{array}{l}\text { Sampled at early exp. phase }(0), 0.5 \text {, } \\
1,2,4, \text { and } 6 \mathrm{~h}\end{array}$ & cDNA microarrays & $\begin{array}{l}\text { Gasch et al. } \\
(2000)\end{array}$ \\
\hline $\begin{array}{l}\text { From glucose grown to amino acid starvation + nitrogen } \\
\text { limitation }\end{array}$ & & $\begin{array}{l}\text { Sampled at early exp. phase (0), } 0.5 \text {, } \\
1,2,4,8,12 \mathrm{~h}, 1,2,3 \text {, and } 5 \text { days }\end{array}$ & & \\
\hline Aerobic carbon, nitrogen, phosphorus, or sulfur limited & Chemostat at $0.1 \mathrm{~h}^{-1}$ & Sampled at steady state & $\begin{array}{l}\text { Affymetrix Yeast } \\
\text { Genome S98 Array }\end{array}$ & $\begin{array}{l}\text { Boer et al. } \\
(2003)\end{array}$ \\
\hline Glucose, ethanol, ammonium, phosphate, or sulfate limited & Chemostat at $0.1 \mathrm{~h}^{-1}$ & $\begin{array}{l}\text { Sampled at steady state and } \\
\text { starvation phase }\end{array}$ & $\begin{array}{l}\text { Arrays supplied by } \\
\text { Hoheisel }\end{array}$ & $\begin{array}{l}\text { Wu et al. } \\
(2004)\end{array}$ \\
\hline Carbon, nitrogen, phosphorus, or sulfur limited & $\begin{array}{l}\text { Chemostat at } 0.07,0.1 \\
\text { and } 0.2 \mathrm{~h}^{-1}\end{array}$ & Sampled at steady state & $\begin{array}{l}\text { Affymetrix Yeast } \\
\text { Genome S98 Array }\end{array}$ & $\begin{array}{l}\text { Castrillo et al. } \\
(2007)\end{array}$ \\
\hline $\begin{array}{l}\text { Glucose, ammonium, sulfate, phosphate, uracil, or leucine } \\
\text { limited }\end{array}$ & $\begin{array}{l}\text { Chemostat at } 0.05,0.1 \text {, } \\
0.15,0.2,0.25 \text {, and } \\
0.3 \mathrm{~h}^{-1}\end{array}$ & Sampled at steady state & $\begin{array}{l}\text { Agilent Yeast Oligo } \\
\text { Microarray (V2) }\end{array}$ & $\begin{array}{l}\text { Brauer et al. } \\
(2008)\end{array}$ \\
\hline Histidine-, lysine-limited & $\begin{array}{l}\text { Chemostat at } 0.05,0.1 \text {, } \\
0.15,0.2,0.25 \text {, and } \\
0.3 \mathrm{~h}^{-1}\end{array}$ & Sampled at steady state & $\begin{array}{l}\text { Agilent Yeast Oligo } \\
\text { Microarray }\end{array}$ & $\begin{array}{l}\text { Slavov and } \\
\text { Botstein (2013) }\end{array}$ \\
\hline \multicolumn{5}{|l|}{ Transient nutrient changes } \\
\hline Glucose (1 $\mathrm{g} / \mathrm{L})$ pulse to glucose-limited & Chemostat at $0.05 \mathrm{~h}^{-1}$ & $0,0.5,1,2,3.5,5$, and $5.5 \mathrm{~min}$ & $\begin{array}{l}\text { Affymetrix Yeast } \\
\text { Genome S98 Array }\end{array}$ & $\begin{array}{l}\text { Kresnowati } \\
\text { et al. (2006) }\end{array}$ \\
\hline $\begin{array}{l}\text { Anaerobic glucose (200 mM) pulse to aerobic } \\
\text { glucose-limited }\end{array}$ & Chemostat at $0.1 \mathrm{~h}^{-1}$ & $0,5,10,30,60$, and $120 \mathrm{~min}$ & $\begin{array}{l}\text { Affymetrix Yeast } \\
\text { Genome S98 Array }\end{array}$ & $\begin{array}{l}\text { van den Brink } \\
\text { et al. (2008) }\end{array}$ \\
\hline Switch to glucose-free or ammonium-free medium & Filter-cultures & $\begin{array}{l}\text { Sampled at exp. phase (0), 10, 30, } \\
60,120,240 \text {, and } 480 \mathrm{~min}\end{array}$ & $\begin{array}{l}\text { Agilent Yeast Oligo } \\
\text { Microarray (V2) }\end{array}$ & $\begin{array}{l}\text { Bradley et al. } \\
(2009)\end{array}$ \\
\hline $\begin{array}{l}\text { Glucose }(2 \% \mathrm{w} / \mathrm{v}) \text { pulse to glucose-limited and ammonium } \\
(0.3 \% \mathrm{w} / \mathrm{v}) \text { pulse to ammonium-limited }\end{array}$ & Chemostat at $0.1 \mathrm{~h}^{-1}$ & $\begin{array}{l}\text { Sampled at } 0,20,40,60 \mathrm{~s}, 8,16,24 \\
32 \mathrm{~min}, 1,2,3,4,5 \text {, and } 7 \mathrm{~h}\end{array}$ & $\begin{array}{l}\text { Affymetrix Yeast } \\
\text { Genome 2.0 Array }\end{array}$ & $\begin{array}{l}\text { Dikicioglu et al. } \\
(2011,2012)\end{array}$ \\
\hline \multicolumn{5}{|l|}{ Nutrient signaling } \\
\hline $\begin{array}{l}\text { Galactose }(2 \%) \text { or glucose }(2 \%) \text { addition to glycerol grown } \\
\text { cells }\end{array}$ & NA & $\begin{array}{l}\text { Sampled at } \mathrm{OD}_{600}=0.25(0), 20,40 \\
60, \text { and } 80 \mathrm{~min}\end{array}$ & $\begin{array}{l}\text { Agilent Yeast Oligo } \\
\text { Microarray }\end{array}$ & $\begin{array}{l}\text { Zaman et al. } \\
(2009)\end{array}$ \\
\hline Glucose (4\%) addition to ethanol grown cultures & NA & $\begin{array}{l}\text { Sampled at early exp. phase (0), and } \\
30 \text { min }\end{array}$ & $\begin{array}{l}\text { Affymetrix Yeast } \\
\text { Genome S98 Array }\end{array}$ & $\begin{array}{l}\text { Livas et al. } \\
\text { (2011) }\end{array}$ \\
\hline Switch to glucose, nitrogen, or amino acid-free medium & Shake flasks & $\begin{array}{l}\text { Sampled at } \mathrm{OD}_{600}=0.60(0), 20 \mathrm{~min} \\
\text { Sampled at steady state }\end{array}$ & $\begin{array}{l}\text { Agilent Yeast Oligo } \\
\text { Microarray (V2) }\end{array}$ & $\begin{array}{l}\text { Hughes Hallett } \\
\text { et al. (2014) }\end{array}$ \\
\hline $\begin{array}{l}\text { Glutamine }(400 \mathrm{mg} / \mathrm{L}) \text { pulse to proline grown cultures from } \\
\text { proline + glutamine grown cultures to glutamine depletion }\end{array}$ & Batch reactor & $\begin{array}{l}\text { Sampled at } 0,3,7,10,14,24,56 \text {, } \\
\text { and } 120 \mathrm{~min}\end{array}$ & $\begin{array}{l}\text { Affymetrix Yeast } \\
\text { Genome 2.0 Array }\end{array}$ & $\begin{array}{l}\text { Oliveira et al. } \\
(2015)\end{array}$ \\
\hline \multirow[t]{2}{*}{ Anaerobic glucose limited } & $\begin{array}{l}\text { Chemostat at } 0.025 \\
0.05,0.1 \mathrm{~h}^{-1}\end{array}$ & Sampled at steady state & $\begin{array}{l}\text { Affymetrix Yeast } \\
\text { Genome S98 Array }\end{array}$ & $\begin{array}{l}\text { Bisschops } \\
\text { et al. (2014) }\end{array}$ \\
\hline & Retentostat & Sampled at $2,9,16$, and 20 days & & \\
\hline
\end{tabular}

caused by different oxidative agents. Since the hydrogen peroxide is a natural ROS as a by-product of the aerobic metabolism and was most extensively used as a model system for oxidative stress, we will mainly focus in this review on the studies where the oxidative stress was induced by hydrogen peroxide treatment.

The dynamic transcriptomic response to the addition of hydrogen peroxide and menadione into batch cultures was first investigated by Gasch et al. (2000) among other environmental stresses for a period of 2-3 h. The genes encoding superoxide dismutases, gluthatione peroxidases, thiol-specific antioxidants, thioredoxin, thioredoxin reductases, glutaredoxin, and glutaredoxin reductase in addition to ESR genes were found to be specifically upregulated in response to both chemicals. Transcriptomic response of YAP1 deleted yeast strain indicated that Yaplp is an important regulator of the OSR. Causton et al. (2001) have also investigated the transcriptomic response of yeast cells to hydrogen peroxide similarly and reported the specific upregulation of $R O X 1$, which is a repressor of hypoxic genes. Comparative transcriptomic analysis of the wild-type, yap $1 \Delta$, yap $2 \Delta$, yap $1 \Delta$ yap $2 \Delta$, yeast cells after treatment with hydrogen peroxide showed that these proteins are regulators of different biological processes in OSR (Cohen et al., 2002).

TOR kinase complex I pathway is known to be involved in the response to a vast variety of stresses (Loewith and Hall, 2011). Hughes Hallett et al. (2014) examined the TORC1 pathway process information by investigating transcriptional reorganization of yeast cells in response to various perturbations, including oxidative stress induced with hydrogen peroxide using an integrative approach. The analysis of two different modules indicated that the genes in the TORC1-Sch9 pathway were downregulated and the expression levels of the genes in the TORC1-PP2A were not or little affected under oxidative shock. The investigation of the phosphorylation levels of the proteins regulated by PP2A by bandshift assay showed that Nprlp and Gln3p are dephosphorylated but 
Nnk1p remained phosphorylated upon oxidative stress. These results indicated that TORC1-PP2A-branch signaling is weak or moderate under oxidative stress. Furthermore, the analysis of three yeast strains that stop the transmission of the signal from Npr2p/Npr3p, Gtr1p/Gtr2p, and Rho1p to TORC1-Sch9 signaling and SNF1 deleted strains resulted in the observation that these proteins do not have any effect on this signaling under oxidative stress as well as under osmotic and heat stresses.

Investigation of the dynamic transcriptional response of yeast cells to oxidative stress induced by the addition of CHP at midexponential phase under fully controlled conditions revealed early transcriptional events (Sha et al., 2013). Approximately $54 \%$ of the genes that are regulated by Msn2p/Msn4p were also found to be significantly and differentially expressed after the treatment with CHP. YAP1 was found to be upregulated after 6 and $20 \mathrm{~min}$ of induction and $52 \%$ of its targets were differentially and significantly expressed upon oxidative stress. HMS2, MET28, YAP5, NUT2, ROX1, and SUT2 encoding transcriptional factors were also found to be induced during the early response within the first 6 min after the addition of CHP. MET1, MET12, MET16, MET22, MET3, MET8, CYS3, and STR3 regulating sulfur metabolism, which are targets of MET28, were upregulated within 20 min. Other members of the YAP family (YAP3, YAP5, and YAP7) were also upregulated in the early response to CHP. Drug resistance-related proteins, the proteins involved in cell wall and cytoskeleton metabolism, and another group of genes of unknown function were found significantly induced within $6 \mathrm{~min}$ after the stress induction and returned immediately to their basal levels. A transient repression of the genes involved in cell growth, DNA replication, transcription, and translation was observed within this interval. The genes associated with mitochondrial function and vesicle trafficking were also transiently downregulated in this early period. The transcript levels of the genes that are involved in gluthatione, glutaredoxin, and thioredoxin systems and the genes encoding ROS removing enzymes were induced within this early period. The genes encoding the enzymes of the oxidative branch of the pentose phosphate pathway were upregulated, whereas the branch leading to the synthesis of nucleic acids was repressed. The transcription factor Rpn $4 p$ that is regulator of the synthesis of the proteasome subunits was induced earlier than the genes encoding of these subunits to cope with the removal of the accumulated oxidized proteins. A comparative analysis of the results with previous studies (Gasch et al., 2000; Causton et al., 2001), whereas the hydrogen peroxide was used to induce the oxidative stress, revealed the induction of the ESR genes, and the genes involved in the glutathione metabolism and the pentose phosphate pathway. The biological processes associated with transcription and translation were downregulated in all three studies. The induction of cell wall and membrane was specific for the antioxidant CHP. The genes associated with mitochondrial processes were downregulated in response to CHP, whereas upregulated in response to hydrogen peroxide (Sha et al., 2013).

In a recent study, Zhao et al. (2015) investigated the transcriptional response of a strain, which has higher peroxide tolerance ability to $2 \mathrm{mM}$ hydrogen peroxide exposure in comparison to that of control strain. The genes involved in carbohydrate metabolism, fatty acid degradation, glycolysis/gluconeogenesis, peroxisomal matrix, pyruvate metabolism, amino acid metabolism, and nucleotide repair pathways were found to be significantly and differentially expressed between two strains in response to hydrogen peroxide. MAP kinase and CAMP-PKA signaling pathways, which were significantly enriched by the genes responsive to oxidative perturbation, were identified to be involved in the oxidative tolerance of the mutant strain.

A whole-genome scale analysis at different omics levels revealed that Slf1p, which is La-related protein, is involved in the translational control of oxidative stress induced by hydrogen peroxide (Kershaw et al., 2015). Deletion and mutated strains of SLF1 were used in this study and cultures were treated with hydrogen peroxide for 10 or $60 \mathrm{~min}$ to induce oxidative stress.

The details of all these oxidative perturbation experiments in S. cerevisiae cells are summarized in Table 2. These studies, focused on the response of $S$. cerevisiae to oxidative stress, revealed a set of regulators including Yap1p and its homologs, Skn7p, Msn2p, and Msn4p and their selective targets. However, construction of a quantitative model, which incorporate sensing, signaling, and regulation, could not be constructed. It should also be noted that further studies are required to identify missing information coming from a unique experimental platform and carefully designed perturbation experiments.

\section{TRANSCRIPTOMIC RESPONSE TO THE CHANGING TEMPERATURES}

Yeast cells encounter rapid and large differences in temperature in nature, and industrial strains are being optimized to grow at certain temperatures, depending on the production process. Therefore, in order to understand the mechanisms for adapting to and showing tolerance to different temperatures, perturbation experiments were designed and performed. The adaptation of wine strains to cold is also important to improve the aroma of the wine. Yeast strains were stored at freezing temperatures, and it is critical to comprehend storage temperature effects on the viability/physiology of the cells. Therefore, the transcriptional response of yeast cells to different temperatures was extensively studied.

\section{Heat Shock or Adaptation to Higher Temperatures}

Temporal genome-wide transcriptional changes of wild-type and MSN2/MSN4 deleted yeast cells in response to a temperature shift from 25 to $37^{\circ} \mathrm{C}$ was first investigated by Gasch et al. (2000). The changes in the expression levels of ESR genes were observed within the first minutes after the heat shock, and the majority of these genes were found to be regulated by Msn2p/Msn4p by the investigation of the transcriptomic response of double deleted mutants to heat shock. The genes involved in protein folding chaperons were observed to be induced later. Analysis of the transcriptomic response to a similar temperature shift has also provided further support for these findings (Causton et al., 2001).

A comparative genome-wide analysis including the transcriptional analysis of wild-type and $r p d 3 \Delta$ strains grown at 25 and $39^{\circ} \mathrm{C}$ for 20 min resulted in the finding that RpdL3 histone deacetylase complex is involved in the partial regulation of gene 
TABLE 2 | Oxidative perturbation experiments in S. cerevisiae.

\begin{tabular}{|c|c|c|c|c|}
\hline Perturbation & Experiment type & Exposure (sampling) time & Measurement technique & Reference \\
\hline $\begin{array}{l}\text { Hydrogen peroxide }(0.30 \mathrm{mM}) \text { addition at } \\
\text { early exp. phase }\end{array}$ & Shake flasks & $\begin{array}{l}0,10,20,30,40,50,60,80,100, \\
\text { and } 120 \mathrm{~min}\end{array}$ & cDNA microarrays & Gasch et al. (2000) \\
\hline $\begin{array}{l}\text { Hydrogen peroxide }(0.40 \mathrm{mM}) \text { addition at } \\
\text { mid-exp. phase }\end{array}$ & Shake flasks & $0,10,20,40,60$, and $100 \mathrm{~min}$ & Affymetrix YE6100 gene chips & Causton et al. (2001) \\
\hline $\begin{array}{l}\text { Hydrogen peroxide }(0.6 \mathrm{mM}) \text { addition at } \\
\text { mid-exp. phase }\end{array}$ & NA & $1 \mathrm{~h}$ & Oligonucleotide arrays & Cohen et al. (2002) \\
\hline $\begin{array}{l}\text { Hydrogen peroxide }(2 \mathrm{mM}) \text { addition at mid- } \\
\text { exp. phase }\end{array}$ & Shake flasks & $0,20 \mathrm{~min}$ & Agilent Yeast Oligo Microarray (V2) & $\begin{array}{l}\text { Hughes Hallett et al. } \\
\text { (2014) }\end{array}$ \\
\hline CHP $(190 \mu \mathrm{M})$ addition at mid-exp. phase & Batch bioreactor & $0,3,6,12$, and $20 \mathrm{~min}$ & Affymetrix Yeast Genome S98 Array & Sha et al. (2013) \\
\hline Growth with 2 mM hydrogen peroxide & Shake flasks & Sampled at mid-exp. phase & RNA-sequencing & Zhao et al. (2015) \\
\hline $\begin{array}{l}\text { Hydrogen peroxide }(0.4 \mathrm{mM}) \text { addition at } \\
\text { mid-exp. phase }\end{array}$ & NA & 0,15 , and $60 \mathrm{~min}$ & RNA-sequencing & Kershaw et al. (2015) \\
\hline
\end{tabular}

expression upon heat exposure. This study indicated the important role of the chromatin modifications in the reorganization of transcriptomic response to the heat exposure. Hsf1p and Msn2p/ Msn4p are main regulators of the heat shock, and this complex has a role in the activation of the genes regulated by Msn2p/ Msn4p (Ruiz-Roig et al., 2010).

Mensonides et al. (2013) investigated the transcriptome of S. cerevisiae in response to a temperature shift from 28 to $41^{\circ} \mathrm{C}$ to understand the adaptation of yeast cells to high temperature bioprocesses, over a period of $6 \mathrm{~h}$, in batch cultures. In the initial response during the first hour, in which the cell growth was impaired, genes involved in energy metabolism, trehalose metabolism, the genes encoding molecular chaperones were most significantly induced, and the genes coding for components of translation and transcription machinery were provisionally downregulated. Biological processes related to amino acid biosynthesis, nucleotide metabolism, ion transport, and rRNA biosynthesis were found to be induced after $60 \mathrm{~min}$ within the cell growth permissive period. The upregulation of stress responsive genes was also observed during this period except the genes involved in trehalose metabolism. Transporters and the genes associated with purine metabolism were downregulated. The genes involved in the PKC1 pathway, also known as cell wall integrity pathway, were found to be upregulated upon heat shock and remained active for about $1 \mathrm{~h}$ during heat exposure.

Hughes Hallett et al. (2014) investigated the effect of the heat stress on the TORC1 pathway by exposing yeast cells to $42^{\circ} \mathrm{C}$ for $20 \mathrm{~min}$. The response was similar to the response of yeast cells to oxidative stress; TORC1-Sch9 signaling was blocked, whereas TORC1-PP2A-branch signaling was weak or moderate.

\section{Cold Shock or Adaptation to Cold}

Acclimatization/adaptation of yeast cells to cold was also extensively studied through perturbation experiments. First perturbation experiments to investigate the dynamic transcriptomic response of yeast cells to a temperature shift from 37 to $25^{\circ} \mathrm{C}$ were carried out by Gasch et al. (2000). Unlike to the response observed in a temperature shift from 25 to $37^{\circ} \mathrm{C}$, the ESR genes were repressed under this condition and showed a very rapid transition to steady-state characteristics at $25^{\circ} \mathrm{C}$.
Sahara et al. (2002) performed perturbation experiments to analyze the dynamic transcriptional response in wild-type yeast cells upon exposure to $10^{\circ} \mathrm{C}$ for $8 \mathrm{~h}$. Genes involved in rRNA synthesis and the biosynthesis of ribosomal proteins were upregulated in the early phase within $30 \mathrm{~min}$ and in the middle phase within $2 \mathrm{~h}$, respectively. General stress genes, including the genes involved in trehalose and glycogen biosynthesis, were observed to be induced in the late phase. Additionally, data indicated that cAMP-PKA pathway might have a role in the regulation of these genes. In another study aiming to investigate the adaptation of yeast cells to cold, wild-type and MSN2/MSN4 deleted yeast cells were exposed to $10^{\circ} \mathrm{C}$ for varied time periods changing up to $60 \mathrm{~h}$. This study has also provided additional support that ESR genes, including the genes encoding various heat shock proteins and gluthatione/glutaredoxin system, were upregulated during late cold response, which is dependent on Msn2p/Msn4p. The genes involved in RNA metabolism and lipid metabolism were induced during early cold response which was Msn2/Msn4 independent (Schade et al., 2004).

The analysis of the transcriptomic response of yeast cells grown in batch cultures at $25^{\circ} \mathrm{C}$ and exposed to near-freezing temperature for different periods of time ranging from 6 to $48 \mathrm{~h}$ revealed that the genes involved in trehalose and glycogen synthesis and the genes encoding phospholipids, mannoproteins, cold shock proteins, heat shock proteins, and glutathione were upregulated for cold adaptation. The downregulation of the genes involved in protein synthesis at $4^{\circ} \mathrm{C}$ is in agreement with the observed delay in growth (Murata et al., 2006).

Tai et al. (2007) studied the genome-wide expression of $S$. cerevisiae cells in response to suboptimal temperatures at steady state. Yeast cells were grown in anaerobic glucoselimited and ammonium-limited chemostat cultures at a dilution rate of $0.03 \mathrm{~h}^{-1}$, at 12 and $30^{\circ} \mathrm{C}$. At low temperature $\left(12^{\circ} \mathrm{C}\right)$, transcription levels of ribosome-biogenesis genes were increased, and in contrast to batch cultures, the expression levels of $88 \%$ of ESR genes were decreased. A group of genes involved in nuclear export and ribosome biogenesis was found to be upregulated and the genes involved in carbohydrate metabolism, transport, and response to stimulus were downregulated under both nitrogen and carbon limited 
conditions. This study revealed adaptational differences between the long-term exposure and a rapid shift to low temperature pointing out no need for trehalose and glycogen for the cold adaptation at steady state.

Comparative transcriptomic analysis of the effect of the low temperature $\left(15^{\circ} \mathrm{C}\right)$, between a laboratory and a wine strain grown under anaerobic nitrogen-limited conditions in chemostats resulted in the identification of strain-specific and temperaturedependent genes. The absence of induction of the genes mediated by stress response elements implied that the GSR was repressed under $15^{\circ} \mathrm{C}$ in comparison to $30^{\circ} \mathrm{C}$. The genes involved in trehalose metabolism and in GSR were found to be downregulated, and the genes involved in ribosome biogenesis, RNA processing were upregulated at low temperature in both strains. Integration of the transcriptome with the metabolic topology indicated that glycogen metabolism, amino acid transport, glycolipid biosynthesis, arginine biosynthesis, and allantoin metabolism were affected by the temperature. The transcript levels of the genes involved in sugar uptake and nitrogen metabolism, and transcript levels of genes related to organoleptic properties were significantly different between the two strains. The expression level of HSF1, encoding a heat shock transcription factor, which is active under diverse stress conditions, was lower at $15^{\circ} \mathrm{C}$ in both strains (Pizarro et al., 2008). García-Ríos et al. (2014) also investigated the adaptation of two different wine strains, grown in chemostat cultures at $0.028 \mathrm{~h}^{-1}$, to $15^{\circ} \mathrm{C}$ in order to improve the wine aroma. The integrative analysis of transcriptome with metabolome and proteome data revealed the upregulation of the sulfur assimilation pathway and glutathione biosynthesis during adaptation to cold and the response to low temperature was found to be strain specific.

The details of all these perturbation experiments in S. cerevisiae cells are summarized in Table 3. One of the common observations was that the set of the genes affected by temperature up- or downshift was different in the early and late phases of the perturbation in batch cultures. MSN2/MSN4-dependent ESR genes were found to be upregulated in the late phase during temperature downshift and in the early phase during the temperature upshift. The majority of the upregulated genes were found to be downregulated upon long-term exposure to lower temperatures in chemostat experiments, where growth rate is constant. TORC1Sch9, cAMP/PKA, and PKC1 pathways were found to be involved in the organization of the transcriptional response to heat shock and induction of the heat shock proteins was mediated by Hsflp. High osmolarity glycerol (HOG) pathway was reported to be involved in the adaptation to cold stress that provokes changes in the membrane fluidity, which are sensed by $\operatorname{Sln} 1 \mathrm{p}$ (Hayashi and Maeda, 2006; Panadero et al., 2006). However, the construction of quantitative models requires further studies as explained in the previous sections and remains as a challenging point.

\section{TRANSCRIPTOMIC RESPONSE TO SALT AND OSMOTIC SHOCK}

Cells exposed to increased osmolarity, leading to water loss and cell shrinking, need to maintain their shape and turgidity. For optimal functioning of biochemical reactions appropriate concentrations of ions are required in the cytosol and organelles. HOG pathway, which is a mitogen-activated protein kinase (MAPK) signal transduction system, was reported to be the major pathway in the adaptation of yeast cells to increased osmolarity by inducing glycerol formation (Hohmann, 2009). Osmostress induction was selected as a model system by several groups to understand the regulation of gene expression by stressactivated kinases and signal transduction. The high osmolarity signaling has been reviewed by Hohmann (2009) and de Nadal and Posas (2015). The detailed description of HOG pathway and

TABLE 3 | Perturbation experiments to monitor the transcriptomic response of S. cerevisiae to the changing temperatures.

\begin{tabular}{|c|c|c|c|c|}
\hline Perturbation & Experiment type & Exposure (sampling) time & Measurement technique & Reference \\
\hline \multicolumn{5}{|c|}{ Heat shock or adaptation to higher temperatures } \\
\hline From 25 to $37^{\circ} \mathrm{C}$ & Shake flasks & $5,15,30$, and $60 \mathrm{~min}$ & cDNA microarrays & Gasch et al. (2000) \\
\hline From 25 to $37^{\circ} \mathrm{C}$ & Shake flasks & $0,15,30,45,60$, and $120 \mathrm{~min}$ & Affymetrix YE6100 gene chips & Causton et al. (2001) \\
\hline 25 or $39^{\circ} \mathrm{C}$ & NA & $20 \mathrm{~min}$ & Agilent Yeast Oligo Microarray & Ruiz-Roig et al. (2010) \\
\hline From 28 to $41^{\circ} \mathrm{C}$ & Batch bioreactor & $0,10,30,60,120,240$, and $360 \mathrm{~min}$ & Affymetrix Yeast Genome S98 Array & Mensonides et al. (2013) \\
\hline From 30 to $42^{\circ} \mathrm{C}$ & Shake flasks & $20 \min$ & Agilent Yeast Oligo Microarray (V2) & Hughes Hallett et al. (2014) \\
\hline \multicolumn{5}{|c|}{ Cold shock or adaptation to cold } \\
\hline From 37 to $25^{\circ} \mathrm{C}$ & Shake flasks & $5,15,30,45,60$, and 90 min & cDNA microarrays & Gasch et al. (2000) \\
\hline From 30 to $10^{\circ} \mathrm{C}$ & NA & $15,30,120,240$, and $480 \mathrm{~min}$ & cDNA microarrays & Sahara et al. (2002) \\
\hline From 30 to $10^{\circ} \mathrm{C}$ & Shake flasks & 10,30, and $120 \mathrm{~min} ;$ some cases $60 \mathrm{~h}$ & DNA microarrays & Schade et al. (2004) \\
\hline From 25 to $4^{\circ} \mathrm{C}$ & Batch/time series (up to 48 h) & $6,12,24$, and $48 \mathrm{~h}$ & cDNA microarrays & Murata et al. (2006) \\
\hline 30 and $12^{\circ} \mathrm{C}$ & Chemostat at $0.03 \mathrm{~h}^{-1}$ & Sampling at steady state & Affymetrix Yeast Genome S98 Array & Tai et al. (2007) \\
\hline 30 and $15^{\circ} \mathrm{C}$ & Chemostat at $0.05 \mathrm{~h}^{-1}$ & Sampling at steady state & Affymetrix Yeast Genome 2.0 Array & Pizarro et al. (2008) \\
\hline 28 and $15^{\circ} \mathrm{C}$ & Chemostat at $0.028 \mathrm{~h}^{-1}$ & Sampling at steady state & Yeast Array & García-Ríos et al. (2014) \\
\hline
\end{tabular}


its repressors were also extensively reviewed (Gehart et al., 2010; Saito and Posas, 2012; Engelberg et al., 2014). Several perturbation experiments were carried out to monitor the genome-wide transcriptomic response of yeast cells to the changing osmolarity in the environment.

The genome-wide analysis of the transcriptomic data of the wild-type and HOG1 deleted yeast cells to saline stress created by the exposure to 0.4 or $0.8 \mathrm{M} \mathrm{NaCl}$ for 10 or $20 \mathrm{~min}$ revealed that the genes involved in carbohydrate, glycerol, trehalose, and glycogen metabolism, the genes involved in the synthesis of ribosomal proteins, protein biosynthesis, and amino acid metabolism were induced after $10 \mathrm{~min}$ exposure to 0.4 or $0.8 \mathrm{M} \mathrm{NaCl}$. The genes associated with stress, signal transduction, and ion homeostasis were also found to be upregulated. The induction in the expression levels of the majority of genes was dependent on Hog1p. The examination of the trancriptomic response after $20 \mathrm{~min}$ indicated that this response was transient (Posas et al., 2000). Rep et al. (2000) analyzed the transcriptional response of the wild-type, HOT1, MSN2 MSN4, and HOG1 deleted strains of S. cerevisiae to osmotic stress created by exposing cells to 0.5 or $0.7 \mathrm{M} \mathrm{NaCl}$ or $0.95 \mathrm{M}$ sorbitol. This study has also revealed the upregulation of the similar set of genes that is reported by Posas et al. (2000), and the induction of the majority of them were found to be Hoglp dependent. Hot1p, which is now known as the transcription factor required for the genes involved in the synthesis of glycerol, was reported to be required for the normal expression of a set of genes of HOG pathway. The authors suggested that MSN2/MSN4 might also be regulated by Hoglp.

Analysis of the dynamic transcriptomic response of $S$. cerevisiae cells grown to mid-log phase and treated with $1 \mathrm{M} \mathrm{NaCl}$ for different periods including $0,10,30$, and 90 min revealed that the number of salinity-induced genes increases over time. Early (10 and $30 \mathrm{~min}$ ) transcriptional response genes were found to be involved in nucleotide and amino acid metabolism, intracellular transport, protein synthesis, and destination. A few components of signaling pathways were also found upregulated in this phase. Highly expressed transcripts identified after $90 \mathrm{~min}$ of the treatment included salinity stress-induced genes, transporters of the major facilitator superfamily, the genes involved in the metabolism of energy reserves, nitrogen and sulfur compounds biosynthesis, and lipid, fatty acid/isoprenoid biosynthesis. The genes involved in glycerol biosynthesis (GPD1/2, GPP1/2) were observed to be upregulated at all time points (Yale and Bohnert, 2001).

The analysis of the dynamic transcriptomic response of wild-type and strains that are blocked at various points in the HOG pathway, to various concentrations of $\mathrm{KCl}$ and $1 \mathrm{M}$ sorbitol revealed that Hog1p functions during gene induction and repression, cross talk inhibition, and in governing the regulatory period. Both branches of the HOG pathway were found to be active at high osmolarity and Ssk-Sln pathway has an important role in response to modest osmolarity (O'Rourke and Herskowitz, 2004).

Fine-tuning of the response to osmotic stress at translational level was also examined by several investigators. Melamed et al. (2008) investigated the translational response of yeast cells to high osmotic stress and its correlation with the transcriptomic response. This study revealed the accumulation of non-translated RNA corresponding to a set of genes. Most of the translationally regulated genes were found to be independent of the HOG pathway. The translational regulation of the HOG pathway-dependent genes was found to be mediated by Publp, and it has been suggested that the involvement of additional signaling pathways in the coordination of translational regulation. Analysis of the correlation with transcription and translatome, by monitoring the affinity tagged ribosomes, indicated that changes in the transcriptome are well correlated with translatome when the yeast cells were exposed to $1 \mathrm{M}$ sorbitol for $10 \mathrm{~min}$ to induce a severe osmotic stress and less correlated with the mild stress (Halbeisen and Gerber, 2009). Warringer et al. (2010) reported that the translationally regulated transcripts were dependent on Hoglp and Rck 2 p after hyperosmotic shock.

A yeast quantitative model of the Hog1 MAPK-dependent osmotic stress response was constructed by integrating immunoprecipitation data (ChIP-chip) with the transcriptome obtained from the analysis of single- and multiple-mutant strains (total of 31 different strains) exposed to $0.4 \mathrm{M} \mathrm{KCl}$ for $20 \mathrm{~min}$ by Capaldi et al. (2008). This model revealed the interaction of Hog1 and Msn 2/4 pathways in information processing and regulation of gene expression in response to osmotic stress, which is context dependent. Chasman et al. (2014) have recently reported a very detailed integrative study on the pathway connectivity and the coordination of the signal in yeast cells in response to $0.7 \mathrm{M}$ $\mathrm{NaCl}$. The transcriptomic data from 16 relevant mutants, which are carrier of the deletions in the genes known to be involved in the $\mathrm{NaCl}$-induced acquired stress tolerance, was integrated with protein interaction data, and phospho-proteomic changes. This study shed light into the regulation and coordination of ESR genes and RNA Pol II was found to be key decision point in the coordination of balance between induced and repressed ESR. Cdc14p was found to be a critical integrator linking HOG and CK2 signaling, connecting to other pathways, including TORC1 and Ras/cAMP/PKA.

An integrative analysis carried out by Hughes Hallett et al. (2014), to investigate the effect of osmotic stress on the TORC1 pathway process information, revealed that the genes in the TORC1-Sch9 pathway were downregulated, and the expression levels of the genes in the TORC1-PP2A were not or little affected under osmotic conditions created with $0.4 \mathrm{M} \mathrm{KCl}$ for a period of 20 min. TORC1-PP2A-branch signaling was weak, and Npr2p/ Npr3p, Gtr1p/Gtr2p, and Rho1p and Snflp were not involved in this signaling process. MAPK Hog1/p38 was found to be important in the inhibition of TORC1-Sch9 signaling, but not in other stress conditions caused by different perturbations of the system.

A comparative analysis of the transcriptomic response of two $S$. cerevisiae strains, a laboratory strain and a brewing strain, in response to high $\mathrm{NaCl}$ concentrations, revealed that the alterations in the expression levels of genes were larger in the laboratory strain. The response to the lower concentration of salt was rapid than that to the higher concentration in both strains. Under high $\mathrm{NaCl}$ concentration conditions, genes involved in carbohydrate metabolism and energy production were upregulated in both strains. Depending on the transcriptome profiles, target genes to construct a new strain with a better salt tolerance were identified, and the outcome of overexpression of those genes (GPD1, ENA1, and CUP1) was verified under high salinity stress (Hirasawa et al., 2006). 
The details of the perturbation experiments in S. cerevisiae cells in response to salt and osmotic shock are summarized in Table 4. The cellular response of yeast cells to high osmotic perturbation was shown to be controlled by Hog1p, which also regulates the activities of Msn2p/Msn4p and TORC1 signaling pathway. Both branches of the HOG pathway were found to be active at high osmolarity, and Ssk-Sln pathway was shown to have an important role in response to modest osmolarity. A quantitative and explicit network model implicating pathway connectivity and coordination of signaling in response to osmotic stress was constructed using an integrative approach by Capaldi et al. (2008) and Chasman et al. (2014), respectively. However, the signaling dynamics and the identification of common and context-dependent features of oxidative response signaling remain to be elucidated.

\section{TRANSCRIPTOMIC RESPONSE TO PERTURBATIONS IN METAL ION HOMEOSTASIS}

Many essential cofactors in the cell are transient metal ions, and they are functional in a range of biological processes, such as cell energetics, gene regulation, and control of free radicals (Cohen et al., 2000). Although these cations are an essential part of nutrition, they are toxic at elevated levels, causing oxidative stress, or changes in enzyme and protein function, lipid peroxidation, and DNA damage. S. cerevisiae, one of the most intensively studied simple eukaryote, is a good model to study how the metabolism is affected by variations in response to the availability of metal ions due to the high degree of conservation among these mechanisms concerning yeast and other higher eukaryotes. There is a substantial amount of information regarding how $S$. cerevisiae deals with these metals and metalloids and copes with them at toxic levels (Wysocki and Tamás, 2010).

Among these metals, iron and copper are of particular interest due to their ability to donate and accept electrons in vital electron transfer reactions thus establishing themselves irreplaceable roles in many cellular processes (De Freitas et al., 2003). It also shed light on the pathophysiology of the related disorders of these processes in higher eukaryotes caused by the deficiency or the overload of these metal ions (Askwith and Kaplan, 1998).

\section{Response to Iron}

Yeast cells respond to change in the iron availability by regulating the expression of iron transporters at transcriptional level. Aftlp was the first identified transcription factor that has a key role for the stimulation of the iron uptake systems in response to low-iron conditions (Yamaguchi-Iwai et al., 1995). Later, the genes regulated by $A F T 2$, which is the paralog of $A F T 1$, were identified using DNA microarrays. This study revealed that Aft2p encodes a transcription factor that has a role in the regulation of the expression in response to growth under low-iron conditions (Rutherford et al., 2001). Courel et al. (2005) designed the perturbation experiment to study the expression of genes involved in iron homeostasis by comparing the functions of Aft $1 \mathrm{p}$ and $\mathrm{Aft} 2 \mathrm{p}$ in regulation. Comparison of the transcriptome of the wild-type strain and corresponding AFT1 and AFT1 AFT2 deleted mutant cells, grown exponentially under iron-deficient conditions, revealed that Atf1p and its paralog Aft2p regulates the expression of genes related to iron-siderophore transport at the plasma membrane, vacuolar iron transport, and mitochondrial iron metabolism under iron-deficient conditions. Aft $2 p$ was identified to have a more specific role in the regulation of genes related to mitochondrial and vacuolar iron homeostasis, while Aft1p explicitly activates the expression of genes related to cell surface iron uptake systems.

Apart from the response observed in the iron ion transport to maintain the iron ion homeostasis, the genes involved in different metabolic pathways requiring iron-dependent enzymes were identified to be transcriptionally regulated in response to a change in the iron availability to remodel the metabolic activities for more efficient use of iron. Metabolic remodeling of yeast cells to iron deficiency was reviewed in detail by Philpott et al. (2012).

TABLE 4 | Perturbation experiments to monitor the transcriptomic response of S. cerevisiae to salt and osmotic shock.

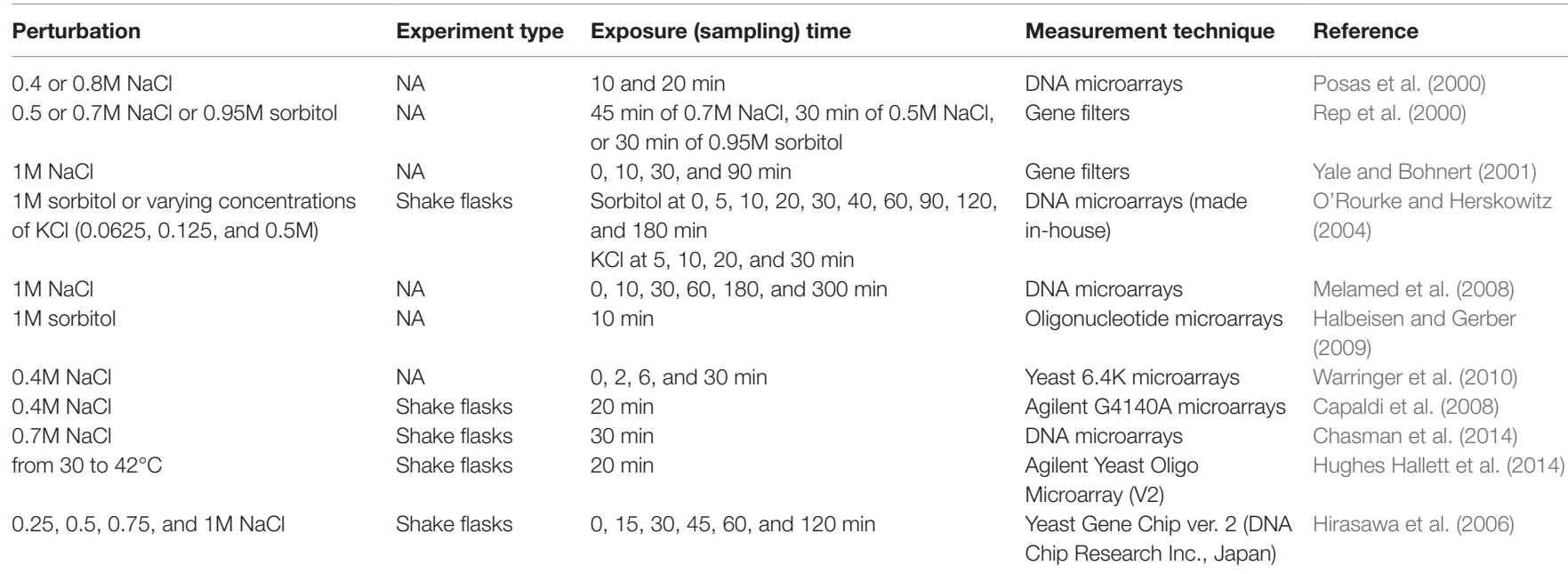


Shakoury-Elizeh et al. (2004) comparatively investigated the transcriptomic response of the wild-type and that of the mutant yeast cells (AFT1 deleted or overexpressing Aft1p) grown in low $(20 \mu \mathrm{M})$, iron sufficient $(100 \mu \mathrm{M})$, and high $(500 \mu \mathrm{M})$ iron conditions, until mid-exponential phase. In addition to the identification of novel target genes of Aft1p, biotin uptake was reported to be upregulated under iron deficiency, while cells preferred to synthesize it when iron is abundant. Similarly, many genes involved in the synthesis and uptake of amino acids that require $\mathrm{Fe}-\mathrm{S}$ proteins were reported to be regulated by iron level. Regulation of glutamate synthesis was identified to be dependent on the iron availability. Its synthesis from ammonia and alpha-ketoglutarate was found to be catalyzed by the enzymes encoded by GDH1 and its paralog GDH3 under iron-deprived conditions. On the other hand, it was synthesized from glutamine and ketoglutarate under iron overloaded conditions through activity of GLT1, which was highly expressed. The integrative analysis of the transcriptome with metabolome data of the yeast cells grown in the presence of low $(10 \mu \mathrm{M})$, optimal $(100 \mu \mathrm{M})$, and high $(330 \mu \mathrm{M})$ concentration of iron for $4 \mathrm{~h}$ revealed that the glucose metabolism, amino acid synthesis, ergosterol, and lipid biosynthesis biological processes were all affected due to the loss in the activities of specific irondependent enzymes under iron deprivation. However, the amino acid homeostasis was not found to be very much affected from iron deficiency. Iron uptake systems were upregulated to preserve the activity of the iron-containing enzymes. It has been suggested that yeast cells do not have a specific machinery to forward iron ions to be used in a specific process under iron deficiency (Shakoury-Elizeh et al., 2010).

Puig et al. (2005) studied and compared the transcriptional response of yeast cells grown to the exponential phase under iron deprivation condition achieved by the addition of iron chelator or in $300 \mu \mathrm{M} \mathrm{Fe}^{1+}$-containing medium. The gene encoding fatty acid desaturase and genes related to sterol biosynthesis were upregulated, and the genes associated with TCA cycle, mitochondrial electron transport chain, heme biosynthesis, and biotin synthesis were downregulated under iron-deprived conditions. The same group further studied the role of $\mathrm{CTH} 2$, which was identified to be specifically induced under iron-deprived conditions, in iron regulon. The transcriptional response of the CTH2 and CTH1 CTH2 deleted mutants to iron deprivation indicated that Cth2p is involved in the targeted degradation of the transcripts coding for proteins involved in multiple $\mathrm{Fe}$-dependent metabolic pathways, including the TCA cycle, respiration, lipid metabolism, heme biosynthesis, and multiple $\mathrm{Fe}-\mathrm{S}$ proteins. It has been suggested that metabolic remodeling in response to iron deprivation is coordinated through targeted degradation of mRNAs encoding proteins, which are involved in Fe-dependent processes and mediated by Cth2p. Further studies conducted by the same group (Puig et al., 2008) identified Cth1p having also an important role in the targeted degradation, specifically mRNAs encoding proteins involved in mitochondrial oxidative phosphorylation, while Cth2p preferentially involved in the targeted degradation of mRNAs of iron-containing enzymes and mRNAs associated with iron homeostasis. These two proteins were also reported to have important roles in the degradation of mRNAs involved in the transport and metabolism. An increase in the glycogen level and activation of Snflp was also observed in response to iron deficiency.

The analysis of the transcriptional response of the wild-type and iron sensitive CCC1 deleted cells to high levels of iron under aerobic and anaerobic conditions, grown in the presence of $3 \mathrm{mM}$ iron for $3 \mathrm{~h}$, revealed that high iron alters the expression of the genes involved in cell-cycle progression, DNA repair, and oxidative response and iron toxicity in the CCC1 deleted cells. The same study also revealed that iron toxicity may not be only due to oxidative damage since the increase in the transcripts indicative of oxidative damage or DNA repair in response to high iron levels was not observed in the cells under anaerobiosis. Iron sensitivity caused by the deletion of CCC1 was reported to be suppressed by the upregulation of the genes encoding mitochondrial iron transporters Mrs3p or Mrs4p or mitochondrial pyrimidine phosphate transporter Rim2p. In this study, it was suggested that cells may decrease cytosolic iron levels by a mechanism that sequester iron ions into mitochondria under iron toxicity (Lin et al., 2011).

In order to investigate the role of the Yap5p transcription factor in the transcriptional reorganization of yeast cells, the transcriptomic response of the YAP5 deleted cells to iron overload was examined after 20 and $60 \mathrm{~min}$ exposure to $2 \mathrm{mM} \mathrm{FeSO}_{4}$ and compared with that of the wild-type yeast cells (Pimentel et al., 2012). In addition to the alterations in the expression levels of the genes involved in iron homeostasis, this study revealed that the genes involved in ribosome biogenesis were downregulated and those of involved in stress response, protein degradation, respiration, lipid, fatty acids, and carbohydrate metabolism were upregulated under high iron-containing conditions, indicating that iron overload causes a GSR. Yap5p was found to be involved in the regulation $G R X 4$, which regulates the nuclear localization of Aft1p, and the expression of CCC1, which is involved in iron storage, was found to be partially regulated by Yap5p. A schematic model to illustrate the hypothetical role of Yap5p under iron overload was also proposed by the authors. The regulation of iron metabolism by low and high iron sensing transcription factors (Aft1p/Aft2p and Yap5p) and post-transcriptional regulation of iron metabolism was reviewed by Outten and Albetel (2013).

\section{Response to Copper}

The transcriptional response to low and high copper levels was reported to be regulated by transcription factors Maclp and Ace1p, respectively (Jungmann et al., 1993). Gross et al. (2000) investigated the genome-wide transcript profiles under copper deprived and excess conditions by exposing the cells to $100 \mu \mathrm{M}$ $\mathrm{CuSO}_{4}$ for $30 \mathrm{~min}$, to identify the targets of Maclp and Acelp. These experiments revealed that Maclp activates the expression of CTR1, CTR3, FRE1, FRE7, YFR055w, and YJL217w under copper deficient conditions. Under copper overloaded conditions Acelp induces the expression of the genes encoding metallothionein that chelates excess copper, Cup1p and Crs5p, and cytosolic copper-zinc superoxide dismutase, Sod1p, which detoxifies superoxide. The expression of the two genes that have roles in iron uptake system, namely FET3, which is required for high-affinity iron uptake, FTR1 which forms complex with Fet3p, were also found to be downregulated under high copper conditions (Gross et al., 2000). 
The genome-wide time-course gene expression analysis during copper starvation and copper overload in the presence of $8 \mu \mathrm{M}$ $\mathrm{CuSO}_{4}$ for a period up to $48 \mathrm{~h}$ highlighted the connection between copper and iron metabolism. In response to copper deprivation, cells induce the expression of copper-independent, non-reductive iron transport genes although the global cellular iron levels did not decrease. Similar to the response observed under iron-deprived conditions, copper deficiency also lead to downregulation of the genes involved in respiration (van Bakel et al., 2005).

Cankorur-Cetinkaya et al. (2013) compared the transcriptional profiles of the wild-type and CCC2 deleted cells under copper deficient and high or low levels of copper-containing conditions by growing yeast cells without copper or $0.04 \mu \mathrm{M}$ or $0.5 \mathrm{mM} \mathrm{CuSO}_{4}$. CCC2 is the human ortholog of human ATP7A and $A T P 7 B$, in which mutations are the cause of Menkes and Wilson diseases, respectively. Experimental design used in this study enabled the identification of the genes and biological processes affected from the deletion of the CCC 2 gene or the changing extracellular copper levels or the interactive effect of both factors. This study also showed the relation between copper and iron metabolisms highlighting the alteration in the transcriptional response to different level of copper availability in the absence of CCC2, which is involved in the copper export from the cytosol. Ribosome biogenesis and copper import were found to be downregulated in reference yeast cells in response to changes from low/deficient copper condition to high copper condition. This study revealed the processes, regulation of which under different copper levels changes depending on the presence or absence of CCC2. The genes involved in iron ion homeostasis, siderophore transport were identified to be upregulated in the reference strain, whereas downregulated in the absence of CCC2 deleted cells in response to high copper levels. The iron homeostasis, siderophore transport, and $\mathrm{NAD}^{+}$metabolism were identified to be downregulated in the deletion mutant under high copper-containing conditions and upregulated under copperdeficient conditions when compared to the reference strain under same conditions. The amino acid metabolism, specifically arginine metabolic process, was also identified to be altered by the interactive effect of both perturbations, and these findings were also supported by the metabolomic analysis. The transcription factors, around which most transcriptomic changes occur, were also identified in this study through integrative analysis of transcriptome and regulome. This integrative analysis indicated that the genes targeted by general oxidative stress inducers, namely Sko1p, Skn7p, Cin5p, Yap1p, and Yap6p, were mostly affected from both perturbations and their interactions.

\section{Response to Other Metal lons}

The transcriptional response of yeast to zinc deficiency was studied in glucose- and ammonium-limited chemostat cultures aerobically and anaerobically (De Nicola et al., 2007). Zincspecific Zap1p regulon, a central transcription factor that is active in response to zinc alterations, was identified to be the regulator of genes involved in carbohydrate storage metabolism. It was found that oxygen and $\mathrm{Zn}$ availability affected a large number of genes, implying a more significant role of $\mathrm{Zn}$ in mitochondrial processes. Wu et al. (2008) used transcriptome profiling of the wild-type and mutant cells, ZAP1 deleted and cells containing plasmids encoding constitutive allele of Zap1, to detect the target genes of Zap1p. Yeast cells were exposed to various concentrations of zinc changing from 3 to $300 \mu \mathrm{M}$ for various periods of time changing from 0.5 to $8 \mathrm{~h}$. In addition to their previous study (Lyons et al., 2000), in which 46 genes were identified to be potential target genes; in this study, they further investigated the role of Zap1p and identified numerous new targets of Zap1-mediated regulation. The transcriptomic response of the Zap1 target genes was shown to have dependency to the level of zinc in the medium. This study revealed that cells induce the genes involved in zinc uptake to maintain the zinc homeostasis in response to a mild zinc deficiency. On the other hand, the genes involved in maintaining secretory pathway and cell wall function, and stress responses were regulated at transcriptional level in response to a severe zinc deficiency. It has been suggested that these group of genes are mainly involved in the adaptation to zinc deficiency.

Jin et al. (2008) investigated the genome-wide response of yeast cells to a $2 \mathrm{~h}$ of exposure to equitoxic concentrations of $\mathrm{Zn}^{2+}, \mathrm{Cd}^{2+}$, $\mathrm{Hg}^{2+}, \mathrm{Cu}^{2+}, \mathrm{Ag}^{+}, \mathrm{Cr}^{6+}$, and $\mathrm{As}^{3+}$ and complemented this study with deletome. Principal component analysis (PCA) and hierarchical clustering of global transcriptomic response indicated that the response was specific for each metal and the response to different concentrations of the same metal were closely related but different. A group of genes, called common metal responsive (CMR) genes, were found to be commonly affected by all metals. The genes involved in metal transport and homeostasis, detoxification of ROS, carbohydrate metabolism, including glycolysis, oxidative phosphorylation, and alcohol metabolism, polyamine transport, and transcription were upregulated. The genes involved in polysaccharide metabolism, G-protein signaling, protein targeting, and transport were downregulated. Some evolutionarily conserved, signal transduction pathways, including cAMP-dependent PKA, protein kinase CK2, and MAPK, were found to be involved in the regulation of responses to the exposure to metals. Msn2p/Msn4p was observed to regulate $10 \%$ of the differentially expressed genes, among the 14 perturbation conditions.

A short-term effect of the moderate amounts of metals on S. cerevisiae cells was investigated (Hosiner et al., 2014). Analysis of the transcriptomic data after $30 \mathrm{~min}$ acquaintance to $\mathrm{Ag}^{+}, \mathrm{Al}^{3+}$, $\mathrm{As}^{3+}, \mathrm{Cd}^{2+}, \mathrm{Co}^{2+}, \mathrm{Hg}^{2+}, \mathrm{Mn}^{2+}, \mathrm{Ni}^{2+}, \mathrm{V}^{+}$, and $\mathrm{Zn}^{2+}$, metals relevant to human health indicated that the metal-specific oxidative defense, including gluthation/thioredoxin and metallothionein systems, and protein degradation processes, including vacuolar protein degradation, proteosomal proteolysis, chaperone complex activities, and Sec19, which regulates vesicle traffic in secretory pathways, were activated in response to all these metal ions. The genes involved in ribosome biogenesis were observed to be downregulated after a short-term exposure to metals. The potential regulators effective under these conditions were predicted via a statistical tool, and the largest group covered the transcription factors Yap1p, Msn2p, Msn4p, Yap7p, and Cad1p, the latter two being the homologs of Yap1p. A comparative analysis with the results obtained after $2 \mathrm{~h}$ exposure to metals (Jin et al., 2008) showed the induction of the genes involved in protein synthesis and a repression of the genes associated with the metal detoxification process. 
The details of all these perturbation experiments in S. cerevisiae cells are summarized in Table 5. All these studies indicated that yeast cells reorganize their transcriptional response and their metabolism upon exposure or deficiency of transition metals.

Since the iron deficiency is the most common, worldwide nutritional disorder, first perturbation experiments related to iron were designed to understand the effect of the iron deficiency on the reorganization and the regulation of transcriptomic response. These studies resulted in the identification of the target genes controlling iron transport and homeostasis as well as the post-transcriptional regulation of the iron-dependent metabolic pathways under iron deficiency. Aft1p, Aft2p, Yap5p, and Snf1p were found to be the major transcription factors in regulation of the cellular reorganization under iron deprivation.

Although a number of experiments were also carried out to understand the effect of the iron overload, the results of these experiments are not comparable due to the use of different iron concentrations and exposure times. A set of carefully designed perturbation experiments should be planned to understand the effect of the iron overload and to reveal the signaling pathway(s) underlying the response to iron overload and deficiency.

Early copper-related genome-wide studies are concentrated on the identification of target genes of two transcriptional factors in response to copper deficiency and copper overload. However, these pioneering studies are not easily comparable due to the differences in experimental design as in the case of iron.

The perturbation experiments carried out by exposing yeast cells to low or high levels of different metal ions for a defined period of time revealed a detailed picture for the organization of the transcriptional response to metals, including copper. Evolutionarily conserved signaling pathways, including cAMP-dependent PKA, protein kinase that coordinate the post-translational regulation of the proteins involved in the glycolysis and gluconeogenesis and the transcriptional regulation of the synthesis of ribosomal protein, CK2 that is involved in ribosome biosynthesis, and MAPK that is involved in apoptosis, differentiation, and stress response were identified to participate in the organization of the response to metals. Msn2p/Msn4p, Yap1p, and its homologs Yap7p and Cad1p were found to be involved in the regulation of a large number of metal responsive genes. However, a quantitative model implicating these results is still missing.

\section{CONCLUSION AND PERSPECTIVE}

Yeast cells may encounter many kinds of environmental perturbations during growth and fermentation, including accumulation of ethanol, weak acids, heat, low pH, ROS, nutrient limitation, and osmotic changes imposed by high concentrations of sugars

TABLE 5 | Perturbation experiments to monitor the transcriptomic response of S. cerevisiae to changes in metal ion homeostasis.

\section{Perturbation}

Response to iron

Deletion or overexpression of AFT2

aft $1 \Delta$ and aft $1 \Delta$ /aft2 $\Delta$ cells grown in iron depletion

Deletion or overexpression of AFT1 under 20, 100, or

$500 \mu \mathrm{M}$ iron-containing conditions

at mid-exp. phase switch from 100 to 10 , or $300 \mu \mathrm{M}$ iron- $\quad \mathrm{NA}$ containing conditions

No iron or $300 \mu \mathrm{M}$ iron-containing conditions NA

cth $1 \Delta$ /cth $2 \Delta$ cells expressing physiological levels of CTH1, NA

CTH2, or vector alone under iron-deficient conditions

$\operatorname{ccc} 1 \Delta$ exposed to $3 \mathrm{mM}$ of iron under aerobic and

anaerobic conditions

$2 \mathrm{mM}$ iron

\section{Response to copper}

Wild-type versus constitutively active Mac1 at mid-exp. phase switch to no copper, or $100 \mu \mathrm{M}$ copper containing conditions

At mid-exp. phase switch to no copper, or $8 \mu \mathrm{M}$ copper containing conditions

Wild-type versus $\operatorname{ccc} 2 \Delta / \operatorname{ccc} 2 \Delta$

No copper, $0.04 \mu \mathrm{M}$ or $0.5 \mathrm{mM}$ copper containing conditions

\section{Other metal ions}

Zinc limitation at aerobic and anaerobic conditions

Zinc replete (various Zn concentrations) and zinc limiting

Equitoxic concentrations of $\mathrm{Zn}^{2+}, \mathrm{Cd}^{2+}, \mathrm{Hg}^{2+}, \mathrm{Cu}^{2+}, \mathrm{Ag}^{+}$,

$\mathrm{Cr}^{6+}$, and $\mathrm{As}^{3+}$

$\mathrm{Ag}^{+}, \mathrm{Al}^{3+}, \mathrm{As}^{3+}, \mathrm{Cd}^{2+}, \mathrm{Co}^{2+}, \mathrm{Hg}^{2+}, \mathrm{Mn}^{2+}, \mathrm{Ni}^{2+}, \mathrm{V}^{+}$, or $\mathrm{Zn}^{2+}$

\section{Experiment type}

Shake flasks

NA

NA

NA

NA

NA

Shake flasks

NA

NA

Batch bioreactor
Exposure (sampling) time

Sampled at OD = 0.4 Sampled at log phase Sampled at mid-log phase

$4 \mathrm{~h}$

Sampled at log phase Sampled at log phase

$3 \mathrm{~h}$

20 and $60 \mathrm{~min}$

60 min of no copper $30 \mathrm{~min}$ of $100 \mu \mathrm{M} \mathrm{CuSO}{ }_{4}$

$0.5,1,2,3,4,24$, and $48 \mathrm{~h}$

Sampled at mid-log phase
DNA microarrays DNA microarrays cDNA microarrays

Affymetrix Yeast Genome 2.0 Array

DNA microarrays

Affymetrix Yeast Genome

S98 Array

Affymetrix microarray

UAVR Yeast 19.2K v1

DNA microarrays

A-UMCU-4 - UMC Utrecht van Bakel et al. (2005)

S. cerevisiae $16 \mathrm{~K}$ array,

version 1.2

Affymetrix Yeast Genome 2.0 Array

Affymetrix Yeast Genome S98 Array

DNA microarray

DNA microarray

Microarrays obtained from Microarray Centre Toronto
Rutherford et al. (2001) Courel et al. (2005) Shakoury-Elizeh et al. (2004)

Shakoury-Elizeh et al.

(2010)

Puig et al. (2005)

Puig et al. (2008)

Lin et al. (2011)

Pimentel et al. (2012)

Gross et al. (2000)

Cankorur-Cetinkaya et al. (2013)

De Nicola et al. (2007)

Wu et al. (2008)

Jin et al. (2008)

Hosiner et al. (2014)
Shake flasks $\quad 30 \mathrm{~min}$

$0.5,1,2,4$, and $8 \mathrm{~h}$
$2 \mathrm{~h}$

\section{.}


(Teixeira et al., 2011; Zhao et al., 2015). In most cases, cells have to cope simultaneously or successively with numerous aspects. Studying these responses is important for optimizing industrial process conditions and designing more robust overproduction strains using a rational design strategy and genetic engineering techniques. In addition to that, such perturbation/response studies are important due to their contribution to our fundamental understanding of microbial metabolism and to unravel drugdisease relationships. Here, we summarized findings on the yeast transcriptome in response to nutritional, osmotic, oxidative, temperature, and transient metal ion perturbations, as such not aimed for an exhaustive literature survey.

Transcriptomic analysis of S. cerevisiae subjected to different types of stress-causing conditions helped us to identify the genes with altered expression as a result of a perturbation and the use of deleted strains for the known transcription factors led to the determination of the affected genes and the up- or downregulated biological processes. However, studies carried out in the first decade since the application of the high-throughput techniques have discrepancies due to the differences in experimental design including the type of the equipment or microarrays, fermentation conditions and mode, selection of control, duration of the exposure to stress-causing agents, and the amount of stress-causing agent. The first perturbation experiments were carried out in batch. Chemostat fermentations were preferred after the elucidation of the relationship between the response and the growth rate. The statistical and bioinformatics tools used to analyze the results are also important features that make the comparative analysis very difficult.

In the last decade, carefully designed perturbation experiments considering prior genetic data and the integration of transcriptome with metabolome, proteome, phospho-proteome, and interactome revealed the presence of some shared signaling pathways, which are activated in response to several environmental perturbations and also the condition dependent response of S. cerevisiae to specific perturbations. Ras/cAMP/PKA signaling pathway, which is involved in cell growth and response to nutrients and stress, and TORC1, which is the main regulator of growth and metabolism in all eukaryotic cells, were found to be common in response to all perturbations considered in this review. Sch9branch signaling and PP2A-branch signaling of TORC1 were reported to be inhibited under glucose starvation, osmotic stress, oxidative stress, and heat stress in yeast cells. Different types of nitrogen starvation and rapamycin were observed to lead to the activation of PP2A-branch signaling of TOR kinase (Hughes Hallett et al., 2014). Snf1p, AMP-activated serine/threonine protein kinase, which is involved in the transcription of glucose repressed genes in yeast, is also a common regulator in organizing the response of yeast cells to several perturbations. In addition to the common signaling pathways, ESR genes, primarily controlled by the transcription factors Msn2p and Msn4p, which are known to be regulated by Ras/cAMP/PKA pathway, and/or by TORC1, are also induced in response to various environmental perturbations. However, the role of the Msn2p and Msn4p for the acquisition of stress tolerance has remained rather obscure. While Berry and Gasch (2008) suggested a significant role of Msn2p and Msn4p in the gain of stress tolerance, Zakrzewska et al. (2011) claimed that these two transcription factors are not functional for the acquisition of severe stress tolerance, but decline in the growth rate is critical for the gain of tolerance. However, the molecular mechanism leading to the development of tolerance, which is of extreme importance for biotechnological applications, requires further examination.

The major goal of system biology is to construct quantitative whole life models for the prediction of cellular response to the changing environment. When we overview the results of a number of studies carried out in the last 15 years, which are focused to elucidate the response to an induced stress using one or several omics technologies, it seems that we are far away to reach this aim at present. However, it should be noted that the efforts, especially on the development of integrative systems biology approaches complemented with accumulated and shared information, continue and guarantee the success in the near future.

\section{Future Prospects}

Yeast cells have established a range of mechanisms in response to environmental and genetic perturbations, in order to adopt themselves to the new condition. This is attained by not only changes in the gene expression levels and protein regulation but also mRNA stability, non-covalent binding of allosteric effectors and post-translational modifications of enzymes are involved (Tripodi et al., 2015). Therefore, despite the large number of perturbation experiments carried out to date, understanding the complete regulatory and signaling networks in response to perturbations requires further carefully designed perturbation experiments complemented with integrative analysis of -omics and new computational approaches (see Figure 1). It should be noted that strain selection and selection of the mutants, which will be incorporated into the study should be carefully planned by incorporating prior genetic knowledge. The complementation of environmental perturbations with genetic perturbations using appropriate mutants will help to characterize the details and coordination of the underlying signaling and regulatory events.

Most of the reviewed articles here used microarray technology for studying transcriptome. Since the RNA-seq technology has been available for several years now, the number of studies employing this technology is expected to accumulate and play a major role in future research. The properties of RNA-seq such as providing more precise measurement of transcript levels, and excluding limitations such as non-specific hybridization and possible signal saturation due to high abundance of transcripts makes it a valuable tool (Wang et al., 2009; Nookaew et al., 2012).

Most of the studies carried out in the past on the yeast transcriptome comprise measurements at single-type point (static). Time-series transcriptome data complemented with quantitative proteome and phospho-proteome reflect the dynamic regulation of gene expression, thus incorporation of such data improves the validity of a quantitative model, derived to predict the activities of genes under a particular condition. The design of new perturbation experiments to monitor dynamic changes at all -omics levels including interactome and metabolome and the development of new computational tools to analyze and integrate this data will possibly facilitate to reveal the underlying regulatory and 


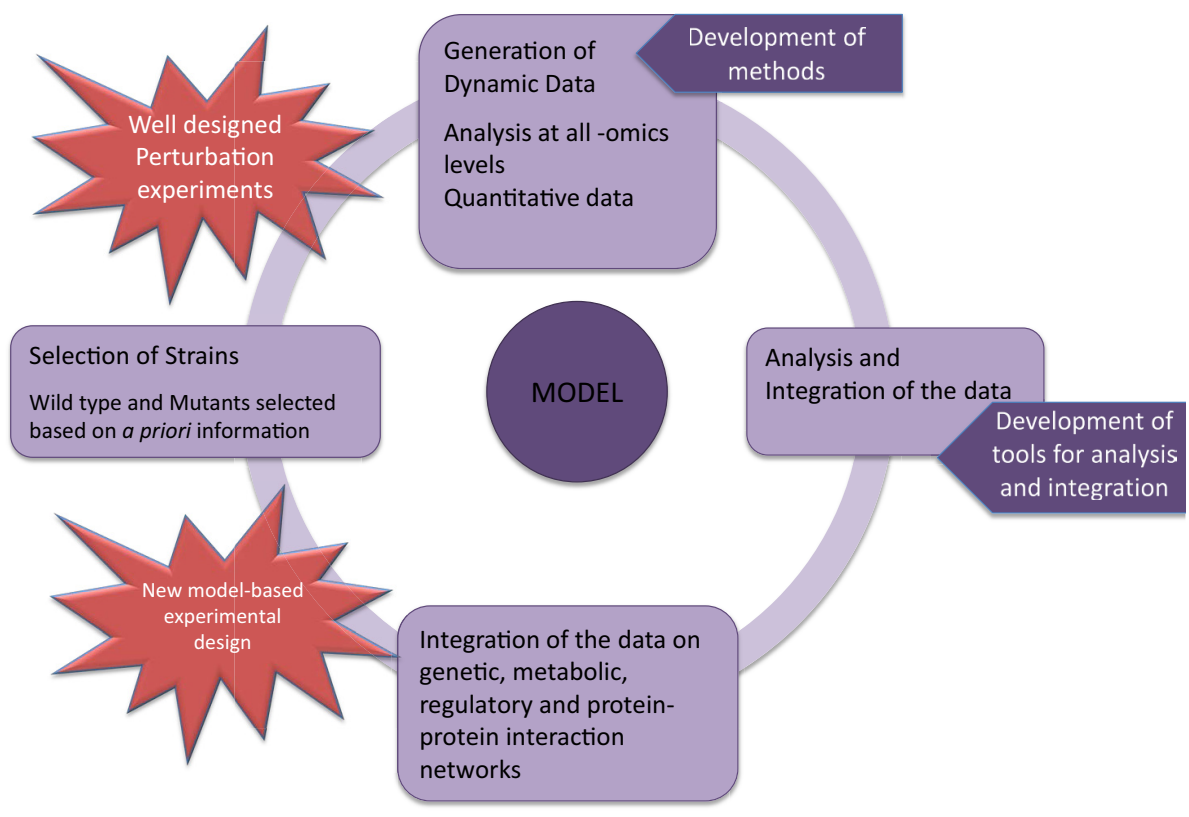

FIGURE 1 | Systems biology-based strategy for the construction of whole-genome models in S. cerevisiae

signaling events and will immensely contribute to improve the predictive capability of models in the near future.

It was not within the scope of this review, but it is noteworthy that the yeast response mechanisms to cope with the presence of a foreign compound, i.e., drug, is an attractive research field to discover drug targets or understand the mechanism of action. Studies on the deletion or overexpressing mutants are considered very important in the understanding of molecular basis of diseases and in finding novel drug targets. For example, the MAP kinase Hog1 is the yeast ortholog of mammalian p38, important for embryonic development and cancer progression (Bradham and McClay, 2006). Consequently, yeast will continue to be one of the major model organisms for systems biology approaches

\section{REFERENCES}

Askwith, C., and Kaplan, J. (1998). Iron and copper transport in yeast and its relevance to human disease. Trends Biochem. Sci. 23, 135-138. doi:10.1016/ S0968-0004(98)01192-X

Bar-Joseph, Z., Gitter, A., and Simon, I. (2012). Studying and modelling dynamic biological processes using time-series gene expression data. Nat. Rev. Genet. 13, 552-564. doi:10.1038/nrg3244

Barrett, T., Wilhite, S. E., Ledoux, P., Evangelista, C., Kim, I. F., Tomashevsky, M., et al. (2013). NCBI GEO: archive for functional genomics data sets - update. Nucleic Acids Res. 41, D991-D995. doi:10.1093/nar/gks1193

Berry, D. B., and Gasch, A. P. (2008). Stress-activated genomic expression changes serve a preparative role for impending stress in yeast. Mol. Biol. Cell 19, 4580-4587. doi:10.1091/mbc.E07-07-0680

Bisschops, M. M., Zwartjens, P., Keuter, S. G., Pronk, J. T., and Daran-Lapujade, P. (2014). To divide or not to divide: a key role of Rim15 in calorie-restricted yeast cultures. Biochim. Biophys. Acta 1843, 1020-1030. doi:10.1016/j. bbamcr.2014.01.026

Boer, V. M., Amini, S., and Botstein, D. (2008). Influence of genotype and nutrition on survival and metabolism of starving yeast. Proc. Natl. Acad. Sci. U.S.A. 105, 6930-6935. doi:10.1073/pnas.0802601105 and specifically designed perturbation experiments will help to develop whole life models.

\section{AUTHOR CONTRIBUTIONS}

All authors participated equally in the preparation of this contribution, have read, and approved the final manuscript.

\section{ACKNOWLEDGMENTS}

We gratefully acknowledge the funding from The Scientific and Technological Research Council of Turkey (TUBITAK) through project no. $114 \mathrm{C} 062$.

Boer, V. M., Crutchfield, C. A., Bradley, P. H., Botstein, D., and Rabinowitz, J. D. (2010). Growth-limiting intracellular metabolites in yeast growing under diverse nutrient limitations. Mol. Biol. Cell 21, 198-211. doi:10.1091/mbc.E09-07-0597

Boer, V. M., de Winde, J. H., Pronk, J. T., and Piper, M. D. (2003). The genomewide transcriptional responses of Saccharomyces cerevisiae grown on glucose in aerobic chemostat cultures limited for carbon, nitrogen, phosphorus, or sulfur. J. Biol. Chem. 278, 3265-3274. doi:10.1074/jbc.M209759200

Boone, C. (2014). Yeast systems biology: our best shot at modeling a cell. Genetics 198, 435-437. doi:10.1534/genetics.114.169128

Bradham, C., and McClay, D. R. (2006). p38 MAPK in development and cancer. Cell Cycle 5, 824-828. doi:10.4161/cc.5.8.2685

Bradley, P. H., Brauer, M. J., Rabinowitz, J. D., and Troyanskaya, O. G. (2009). Coordinated concentration changes of transcripts and metabolites in Saccharomyces cerevisiae. PLoS Comput. Biol. 5:e1000270. doi:10.1371/journal. pcbi. 1000270

Brauer, M. J., Huttenhower, C., Airoldi, E. M., Rosenstein, R., Matese, J. C., Gresham, D., et al. (2008). Coordination of growth rate, cell cycle, stress response, and metabolic activity in yeast. Mol. Biol. Cell 19, 352-367. doi:10.1091/mbc. E07-08-0779

Brazma, A., Hingamp, P., Quackenbush, J., Sherlock, G., Spellman, P., Stoeckert, C., et al. (2001). Minimum information about a microarray experiment 
(MIAME)-toward standards for microarray data. Nat. Genet. 29, 365-371. doi:10.1038/ng1201-365

Cankorur-Cetinkaya, A., Eraslan, S., and Kirdar, B. (2013). Transcriptional remodelling in response to changing copper levels in the Wilson and Menkes disease model of Saccharomyces cerevisiae. Mol. Biosyst. 9, 2889-2908. doi:10.1039/c3mb70276f

Capaldi, A. P., Kaplan, T., Liu, Y., Habib, N., Regev, A., Friedman, N., et al. (2008). Structure and function of a transcriptional network activated by the MAPK Hog1. Nat. Genet. 40, 1300-1306. doi:10.1038/ng.235

Castrillo, J. I., Zeef, L. A., Hoyle, D. C., Zhang, N., Hayes, A., Gardner, D. C., et al. (2007). Growth control of the eukaryote cell: a systems biology study in yeast. J. Biol. 6, 4. doi:10.1186/jbiol54

Causton, H. C., Ren, B., Koh, S. S., Harbison, C. T., Kanin, E., Jennings, E. G., et al. (2001). Remodeling of yeast genome expression in response to environmental changes. Mol. Biol. Cell 12, 323-337. doi:10.1091/mbc.12.2.323

Chasman, D., Ho, Y. H., Berry, D. B., Nemec, C. M., MacGilvray, M. E., Hose, J., et al. (2014). Pathway connectivity and signaling coordination in the yeast stress-activated signaling network. Mol. Syst. Biol. 10, 759. doi:10.15252/ msb. 20145120

Cohen, A., Nelson, H., and Nelson, N. (2000). Metal-Ion Transporters - From Yeast to Human Diseases. Austin, TX: Landes Bioscience. Madame Curie Bioscience Database [Internet].

Cohen, B. A., Pilpel, Y., Mitra, R. D., and Church, G. M. (2002). Discrimination between paralogs using microarray analysis: application to the Yap1p and Yap2p transcriptional networks. Mol. Biol. Cell 13, 1608-1614. doi:10.1091/mbc.01-10-0472

Conrad, M., Schothorst, J., Kankipati, H. N., Van Zeebroeck, G., RubioTexeira, M., and Thevelein, J.M. (2014). Nutrient sensing and signaling in the yeast Saccharomyces cerevisiae. FEMS Microbiol. Rev. 38, 254-299. doi:10.1111/1574-6976.12065

Courel, M., Lallet, S., Camadro, J. M., and Blaiseau, P. L. (2005). Direct activation of genes involved in intracellular iron use by the yeast iron-responsive transcription factor Aft2 without its paralog Aft1. Mol. Cell. Biol. 25, 6760-6771. doi:10.1128/MCB.25.15.6760-6771.2005

De Freitas, J., Wintz, H., Kim, J. H., Poynton, H., Fox, T., and Vulpe, C. (2003). Yeast, a model organism for iron and copper metabolism studies. Biometals 16, 185-197. doi:10.1023/A:1020771000746

de Nadal, E., and Posas, F. (2015). Osmostress-induced gene expression - a model to understand how stress-activated protein kinases (SAPKs) regulate transcription. FEBS J. 282, 3275-3285. doi:10.1111/febs.13323

De Nicola, R., Hazelwood, L. A., De Hulster, E. A., Walsh, M. C., Knijnenburg, T. A., Reinders, M. J., et al. (2007). Physiological and transcriptional responses of Saccharomyces cerevisiae to zinc limitation in chemostat cultures. Appl. Environ. Microbiol. 73, 7680-7692. doi:10.1128/AEM.01445-07

DeRisi, J. L., Iyer, V. R., and Brown, P. O. (1997). Exploring the metabolic and genetic control of gene expression on a genomic scale. Science 278, 680-686. doi: $10.1126 /$ science. 278.5338 .680

Dikicioglu, D., Dunn, W. B., Kell, D. B., Kirdar, B., and Oliver, S. G. (2012). Short- and long-term dynamic responses of the metabolic network and gene expression in yeast to a transient change in the nutrient environment. Mol. Biosyst. 8, 1760-1774. doi:10.1039/c2mb05443d

Dikicioglu, D., Karabekmez, E., Rash, B., Pir, P., Kirdar, B., and Oliver, S. G. (2011). How yeast re-programmes its transcriptional profile in response to different nutrient impulses. BMC Syst. Biol. 5:148. doi:10.1186/1752-0509-5-148

Engelberg, D., Perlman, R., and Levitzki, A. (2014). Transmembrane signaling in Saccharomyces cerevisiae as a model for signaling in metazoans: state of the art after 25 years. Cell. Signal. 26, 2865-2878. doi:10.1016/j.cellsig.2014.09.003

Farrugia, G., and Balzan, R. (2012). Oxidative stress and programmed cell death in yeast. Front Oncol. 2:64. doi:10.3389/fonc.2012.00064

Fazio, A., Jewett, M. C., Daran-Lapujade, P., Mustacchi, R., Usaite, R., Pronk, J. T., et al. (2008). Transcription factor control of growth rate dependent genes in Saccharomyces cerevisiae: a three factor design. BMC Genomics 9:341. doi:10.1186/1471-2164-9-341

García-Ríos, E., López-Malo, M., and Guillamón, J. M. (2014). Global phenotypic and genomic comparison of two Saccharomyces cerevisiae wine strains reveals a novel role of the sulfur assimilation pathway in adaptation at low temperature fermentations. BMC Genomics 15:1059. doi:10.1186/1471-2164-15-1059

Gasch, A. P. (2003). "The environmental stress response: a common yeast response to environmental stresses," in Yeast Stress Responses, Vol. 1, eds Hohmann S. and Mager W. H. (Heidelberg: Springer-Verlag), 11-70.
Gasch, A. P., Spellman, P. T., Kao, C. M., Carmel-Harel, O., Eisen, M. B., Storz, G., et al. (2000). Genomic expression programs in the response of yeast cells to environmental changes. Mol. Biol. Cell 11, 4241-4257. doi:10.1091/mbc.11.12.4241

Gehart, H., Kumpf, S., Ittner, A., and Ricci, R. (2010). MAPKsignalling in cellular metabolism: stress or wellness? EMBO Rep. 11, 834-840. doi:10.1038/embor.2010.160

Giaever, G., Chu, A. M., Ni, L., Connelly, C., Riles, L., Véronneau, S., et al. (2002). Functional profiling of the Saccharomyces cerevisiae genome. Nature 418, 387-391. doi:10.1038/nature00935

Giaever, G., and Nislow, C. (2014). The yeast deletion collection: a decade of functional genomics. Genetics 197, 451-465. doi:10.1534/genetics.114.161620

Gross, C., Kelleher, M., Iyer, V. R., Brown, P. O., and Winge, D. R. (2000). Identification of the copper regulon in Saccharomyces cerevisiae by DNA microarrays. J. Biol. Chem. 275, 32310-32316. doi:10.1074/jbc.M005946200

Halbeisen, R. E., and Gerber, A. P. (2009). Stress-dependent coordination of transcriptome and translatome in yeast. PLoS Biol. 7:e1000105. doi:10.1371/ journal.pbio. 1000105

Hayashi, M., and Maeda, T. (2006). Activation of the HOG pathway upon cold stress in Saccharomyces cerevisiae. J. Biochem. 139, 797-803. doi:10.1093/jb/mvj089

Hirasawa, T., Nakakura, Y., Yoshikawa, K., Ashitani, K., Nagahisa, K., Furusawa, C., et al. (2006). Comparative analysis of transcriptional responses to saline stress in the laboratory and brewing strains of Saccharomyces cerevisiae with DNA microarray. Appl. Microbiol. Biotechnol. 70, 346-357. doi:10.1007/ s00253-005-0192-6

Ho, Y. H., and Gasch, A. P. (2015). Exploiting the yeast stress-activated signaling network to inform on stress biology and disease signaling. Curr. Genet. 61, 503-511. doi:10.1007/s00294-015-0491-0

Hohmann, S. (2009). Controlofhighosmolarity signalling in theyeast Saccharomyces cerevisiae. FEBS Lett. 583, 4025-4029. doi:10.1016/j.febslet.2009.10.069

Hosiner, D., Gerber, S., Lichtenberg-Fraté, H., Glaser, W., Schüller, C., and Klipp, E. (2014). Impact of acute metal stress in Saccharomyces cerevisiae. PLoS ONE 9:e83330. doi:10.1371/journal.pone.0083330

Hughes Hallett, J. E., Luo, X., and Capaldi, A. P. (2014). State transitions in the TORC1 signaling pathway and information processing in Saccharomyces cerevisiae. Genetics 198, 773-786. doi:10.1534/genetics.114.168369

Jin, Y. H., Dunlap, P. E., McBride, S. J., Al-Refai, H., Bushel, P. R., and Freedman, J. H. (2008). Global transcriptome and deletome profiles of yeast exposed to transition metals. PLoS Genet. 4:e1000053. doi:10.1371/journal.pgen.1000053

Jungmann, J., Reins, H. A., Lee, J., Romeo, A., Hassett, R., Kosman, D., et al. (1993). $\mathrm{MAC1}$, a nuclear regulatory protein related to $\mathrm{Cu}$-dependent transcription factors is involved in $\mathrm{Cu} / \mathrm{Fe}$ utilization and stress resistance in yeast. $E M B O$ J. 12, 5051-5056.

Kershaw, C. J., Costello, J. L., Castelli, L. M., Talavera, D., Rowe, W., Sims, P. F., et al. (2015). The yeast La related protein Slf1p is a key activator of translation during the oxidative stress response. PLoS Genet. 11:e1004903. doi:10.1371/journal. pgen.1004903

Kolesnikov, N., Hastings, E., Keays, M., Melnichuk, O., Tang, Y. A., Williams, E., et al. (2015). ArrayExpress update - simplifying data submissions. Nucleic Acids Res. 43, D1113-D1116. doi:10.1093/nar/gku1057

Kresnowati, M. T., van Winden, W. A., Almering, M. J., ten Pierick, A., Ras, C., Knijnenburg, T. A., et al. (2006). When transcriptome meets metabolome: fast cellular responses of yeast to sudden relief of glucose limitation. Mol. Syst. Biol. 2, 49. doi:10.1038/msb4100083

Lin, H., Li, L., Jia, X., Ward, D. M., and Kaplan, J. (2011). Genetic and biochemical analysis of high iron toxicity in yeast: iron toxicity is due to the accumulation of cytosolic iron and occurs under both aerobic and anaerobic conditions. J. Biol. Chem. 286, 3851-3862. doi:10.1074/jbc.M110.190959

Livas, D., Almering, M. J., Daran, J. M., Pronk, J. T., and Gancedo, J. M. (2011). Transcriptional responses to glucose in Saccharomyces cerevisiae strains lacking a functional protein kinase A. BMC Genomics 12:405. doi:10.1186/1471-2164-12-405

Loewith, R., and Hall, M. N. (2011). Target of rapamycin (TOR) in nutrient signaling and growth control. Genetics 189, 1177-1201. doi:10.1534/genetics.111.133363

Lyons, T. J., Gasch, A. P., Gaither, L. A., Botstein, D., Brown, P. O., and Eide, D. J. (2000). Genome-wide characterization of the Zaplp zinc-responsive regulon in yeast. Proc. Natl. Acad. Sci. U.S.A. 97,7957-7962. doi:10.1073/pnas.97.14.7957

Melamed, D., Pnueli, L., and Arava, Y. (2008). Yeast translational response to high salinity: global analysis reveals regulation at multiple levels. RNA 14, 1337-1351. doi:10.1261/rna.864908 
Mensonides, F., Hellingwerf, K., Teixeira de Mattos, M., and Brul, S. (2013). Multiphasic adaptation of the transcriptome of Saccharomyces cerevisiae to heat stress. Food Res. Intern. 54, 1103-1112. doi:10.1016/j.foodres.2012.12.042

Mitchell, A., Romano, G. H., Groisman, B., Yona, A., Dekel, E., Kupiec, M., et al. (2009). Adaptive prediction of environmental changes by microorganisms. Nature 460, 220-224. doi:10.1038/nature08112

Morano, K. A., Grant, C. M., and Moye-Rowley, W. S. (2012). The response to heat shock and oxidative stress in Saccharomyces cerevisiae. Genetics 190, 1157-1195. doi:10.1534/genetics.111.128033

Murata, Y., Homma, T., Kitagawa, E., Momose, Y., Sato, M. S., Odani, M., et al. (2006). Genome-wide expression analysis of yeast response during exposure to 4 degrees C. Extremophiles 10, 117-128. doi:10.1007/s00792-005-0480-1

Nagalakshmi, U., Wang, Z., Waern, K., Shou, C., Raha, D., Gerstein, M., et al. (2008). The transcriptional landscape of the yeast genome defined by RNA sequencing. Science 320, 1344-1349. doi:10.1126/science.1158441

Nookaew, I., Papini, M., Pornputtapong, N., Scalcinati, G., Fagerberg, L., Uhlén, M., et al. (2012). A comprehensive comparison of RNA-Seq-based transcriptome analysis from reads to differential gene expression and cross-comparison with microarrays: a case study in Saccharomyces cerevisiae. Nucleic Acids Res. 40, 10084-10097. doi:10.1093/nar/gks804

Oliveira, A. P., Dimopoulos, S., Busetto, A. G., Christen, S., Dechant, R., Falter, L., et al. (2015). Inferring causal metabolic signals that regulate the dynamic TORC1dependent transcriptome. Mol. Syst. Biol. 11, 802. doi:10.15252/msb.20145475

O'Rourke, S. M., and Herskowitz, I. (2004). Unique and redundant roles for HOG MAPK pathway components as revealed by whole-genome expression analysis. Mol. Biol. Cell 15, 532-542. doi:10.1091/mbc.E03-07-0521

Outten, C. E., and Albetel, A. N. (2013). Iron sensing and regulation in Saccharomyces cerevisiae: ironing out the mechanistic details. Curr. Opin. Microbiol. 16, 662-668. doi:10.1016/j.mib.2013.07.020

Panadero, J., Pallotti, C., Rodríguez-Vargas, S., Randez-Gil, F., and Prieto, J. A. (2006). A downshift in temperature activates the high osmolarity glycerol (HOG) pathway, which determines freeze tolerance in Saccharomyces cerevisiae. J. Biol. Chem. 281, 4638-4645. doi:10.1074/jbc.M512736200

Philpott, C. C., Leidgens, S., and Frey, A. G. (2012). Metabolic remodeling in iron-deficient fungi. Biochim. Biophys. Acta 1823, 1509-1520. doi:10.1016/j. bbamcr.2012.01.012

Pimentel, C., Vicente, C., Menezes, R. A., Caetano, S., Carreto, L., and RodriguesPousada, C. (2012). The role of the Yap5 transcription factor in remodeling gene expression in response to Fe bioavailability. PLoS ONE 7:e37434. doi:10.1371/ journal.pone.0037434

Pizarro, F. J., Jewett, M. C., Nielsen, J., and Agosin, E. (2008). Growth temperature exerts differential physiological and transcriptional responses in laboratory and wine strains of Saccharomyces cerevisiae. Appl. Environ. Microbiol. 74, 6358-6368. doi:10.1128/AEM.00602-08

Posas, F., Chambers, J. R., Heyman, J. A., Hoeffler, J. P., de Nadal, E., and Ariño, J. (2000). The transcriptional response of yeast to saline stress. J. Biol. Chem. 275, 17249-17255. doi:10.1074/jbc.M910016199

Puig, S., Askeland, E., and Thiele, D. J. (2005). Coordinated remodeling of cellular metabolism during iron deficiency through targeted mRNA degradation. Cell 120, 99-110. doi:10.1016/j.cell.2004.11.032

Puig, S., Vergara, S. V., and Thiele, D. J. (2008). Cooperation of two mRNA-binding proteins drives metabolic adaptation to iron deficiency. Cell Metab. 7, 555-564. doi:10.1016/j.cmet.2008.04.010

Regenberg, B., Grotkjaer, T., Winther, O., Fausbøll, A., Akesson, M., Bro, C., et al. (2006). Growth-rate regulated genes have profound impact on interpretation of transcriptome profiling in Saccharomyces cerevisiae. Genome Biol. 7, R107. doi:10.1186/gb-2006-7-11-r107

Rep, M., Krantz, M., Thevelein, J. M., and Hohmann, S. (2000). The transcriptional response of Saccharomyces cerevisiae to osmotic shock. Hotlp and Msn2p/Msn4p are required for the induction of subsets of high osmolarity glycerol pathway-dependent genes. J. Biol. Chem. 275, 8290-8300. doi:10.1074/ jbc.275.12.8290

Ruiz-Roig, C., Viéitez, C., Posas, F., and de Nadal, E. (2010). The Rpd3L HDAC complex is essential for the heat stress response in yeast. Mol. Microbiol. 76, 1049-1062. doi:10.1111/j.1365-2958.2010.07167.x

Rutherford, J. C., Jaron, S., Ray, E., Brown, P. O., and Winge, D. R. (2001). A second iron-regulatory system in yeast independent of Aft1p. Proc. Natl. Acad. Sci. U.S.A. 98, 14322-14327. doi:10.1073/pnas. 261381198
Sahara, T., Goda, T., and Ohgiya, S. (2002). Comprehensive expression analysis of time-dependent genetic responses in yeast cells to low temperature. J. Biol. Chem. 277, 50015-50021. doi:10.1074/jbc.M209258200

Saito, H., and Posas, F. (2012). Response to hyperosmotic stress. Genetics 192, 289-318. doi:10.1534/genetics.112.140863

Schade, B., Jansen, G., Whiteway, M., Entian, K. D., and Thomas, D. Y. (2004). Cold adaptation in budding yeast. Mol. Biol. Cell 15, 5492-5502. doi:10.1091/ mbc.E04-03-0167

Secrier, M., and Schneider, R. (2014). Visualizing time-related data in biology, a review. Brief. Bioinform. 15, 771-782. doi:10.1093/bib/bbt021

Sha, W., Martins, A. M., Laubenbacher, R., Mendes, P., and Shulaev, V. (2013). The genome-wide early temporal response of Saccharomyces cerevisiae to oxidative stress induced by cumene hydroperoxide. PLOS ONE 8:e74939. doi:10.1371/ journal.pone.0074939

Shakoury-Elizeh, M., Protchenko, O., Berger, A., Cox, J., Gable, K., Dunn, T. M., et al. (2010). Metabolic response to iron deficiency in Saccharomyces cerevisiae. J. Biol. Chem. 285, 14823-14833. doi:10.1074/jbc.M109.091710

Shakoury-Elizeh, M., Tiedeman, J., Rashford, J., Ferea, T., Demeter, J., Garcia, E., et al. (2004). Transcriptional remodeling in response to iron deprivation in Saccharomyces cerevisiae. Mol. Biol. Cell 15, 1233-1243. doi:10.1091/mbc. E03-09-0642

Slavov, N., and Botstein, D. (2011). Coupling among growth rate response, metabolic cycle, and cell division cycle in yeast. Mol. Biol. Cell 22, 1997-2009. doi:10.1091/mbc.E11-02-0132

Slavov, N., and Botstein, D. (2013). Decoupling nutrient signaling from growth rate causes aerobic glycolysis and deregulation of cell size and gene expression. Mol. Biol. Cell 24, 157-168. doi:10.1091/mbc.E12-09-0670

Tai, S. L., Daran-Lapujade, P., Walsh, M. C., Pronk, J. T., and Daran, J. M. (2007). Acclimation of Saccharomyces cerevisiae to low temperature: a chemostat-based transcriptome analysis. Mol. Biol. Cell 18, 5100-5112. doi:10.1091/mbc. E07-02-0131

Teixeira, M. C., Mira, N. P., and Sá-Correia, I. (2011). A genome-wide perspective on the response and tolerance to food-relevant stresses in Saccharomyces cerevisiae. Curr. Opin. Biotechnol. 22, 150-156. doi:10.1016/j.copbio.2010.10.011

Thorpe, G. W., Fong, C. S., Alic, N., Higgins, V. J., and Dawes, I. W. (2004). Cells have distinct mechanisms to maintain protection against different reactive oxygen species: oxidative-stress-response genes. Proc. Natl. Acad. Sci. U.S.A. 101, 6564-6569. doi:10.1073/pnas.0305888101

Treu, L., Campanaro, S., Nadai, C., Toniolo, C., Nardi, T., Giacomini, A., et al. (2014). Oxidative stress response and nitrogen utilization are strongly variable in Saccharomyces cerevisiae wine strains with different fermentation performances. Appl. Microbiol. Biotechnol. 98, 4119-4135. doi:10.1007/ s00253-014-5679-6

Tripodi, F., Nicastro, R., Reghellin, V., and Coccetti, P. (2015). Post-translational modifications on yeast carbon metabolism: regulatory mechanisms beyond transcriptional control. Biochim. Biophys. Acta 1850, 620-627. doi:10.1016/j. bbagen.2014.12.010

van Bakel, H., Strengman, E., Wijmenga, C., and Holstege, F. C. (2005). Gene expression profiling and phenotype analyses of $S$. cerevisiae in response to changing copper reveals six genes with new roles in copper and iron metabolism. Physiol. Genomics 22, 356-367. doi:10.1152/physiolgenomics.00055.2005 van den Brink, J., Daran-Lapujade, P., Pronk, J. T., and de Winde, J. H. (2008). New insights into the Saccharomyces cerevisiae fermentation switch: dynamic transcriptional response to anaerobicity and glucose-excess. BMC Genomics 9:100. doi:10.1186/1471-2164-9-100

van Dijk, E. L., Chen, C. L., d’Aubenton-Carafa, Y., Gourvennec, S., Kwapisz, M., Roche, V., et al. (2011). XUTs are a class of Xrn1-sensitive antisense regulatory non-coding RNA in yeast. Nature 475, 114-117. doi:10.1038/nature10118

Wang, Z., Gerstein, M., and Snyder, M. (2009). RNA-Seq: a revolutionary tool for transcriptomics. Nat. Rev. Genet. 10, 57-63. doi:10.1038/nrg2484

Warringer, J., Hult, M., Regot, S., Posas, F., and Sunnerhagen, P. (2010). The HOG pathway dictates the short-term translational response after hyperosmotic shock. Mol. Biol. Cell 21, 3080-3092. doi:10.1091/mbc.E10-01-0006

Wu, C. Y., Bird, A. J., Chung, L. M., Newton, M. A., Winge, D. R., and Eide, D. J. (2008). Differential control of Zap1-regulated genes in response to zinc deficiency in Saccharomyces cerevisiae. BMC Genomics 9:370. doi:10.1186/1471-2164-9-370

Wu, J., Zhang, N., Hayes, A., Panoutsopoulou, K., and Oliver, S. G. (2004). Global analysis of nutrient control of gene expression in Saccharomyces cerevisiae 
during growth and starvation. Proc. Natl. Acad. Sci. U.S.A. 101, 3148-3153. doi:10.1073/pnas.0308321100

Wysocki, R., and Tamás, M. J. (2010). How Saccharomyces cerevisiae copes with toxic metals and metalloids. FEMS Microbiol. Rev. 34, 925-951. doi:10.1111/j.1574-6976.2010.00217.x

Yale, J., and Bohnert, H. J. (2001). Transcript expression in Saccharomyces cerevisiae at high salinity. J. Biol. Chem. 276, 15996-16007. doi:10.1074/jbc.M008209200

Yamaguchi-Iwai, Y., Dancis, A., and Klausner, R. D. (1995). AFT1: a mediator of iron regulated transcriptional control in Saccharomyces cerevisiae. EMBO J. 14, 1231-1239.

Yosef, N., and Regev, A. (2011). Impulse control: temporal dynamics in gene transcription. Cell 144, 886-896. doi:10.1016/j.cell.2011.02.015

Zakrzewska, A., van Eikenhorst, G., Burggraaff, J. E., Vis, D. J., Hoefsloot, H., Delneri, D., et al. (2011). Genome-wide analysis of yeast stress survival and tolerance acquisition to analyze the central trade-off between growth rate and cellular robustness. Mol. Biol. Cell 22, 4435-4446. doi:10.1091/mbc.E10-08-0721

Zaman, S., Lippman, S. I., Schneper, L., Slonim, N., and Broach, J. R. (2009). Glucose regulates transcription in yeast through a network of signaling pathways. Mol. Syst. Biol. 5, 245. doi:10.1038/msb.2009.2
Zaman, S., Lippman, S. I., Zhao, X., and Broach, J. R. (2008). How Saccharomyces responds to nutrients. Annu. Rev. Genet. 42, 27-81. doi:10.1146/annurev. genet.41.110306.130206

Zhao, H., Chen, J., Liu, J., and Han, B. (2015). Transcriptome analysis reveals the oxidative stress response in Saccharomyces cerevisiae. RSC Adv. 5, 22923-22934. doi:10.1039/C4RA14600J

Conflict of Interest Statement: The authors declare that the research was conducted in the absence of any commercial or financial relationships that could be construed as a potential conflict of interest.

Copyright (c) 2016 Taymaz-Nikerel, Cankorur-Cetinkaya and Kirdar. This is an open-access article distributed under the terms of the Creative Commons Attribution License (CC BY). The use, distribution or reproduction in other forums is permitted, provided the original author(s) or licensor are credited and that the original publication in this journal is cited, in accordance with accepted academic practice. No use, distribution or reproduction is permitted which does not comply with these terms. 